\title{
Economix
}

https://economix.fr/

\section{Banks to basics! Why banking regulation should focus on equity}

Document de Travail

Working Paper 2020-2
Pierre Durand Gaëtan Le Quang 


\title{
Banks to basics! Why banking regulation should focus on equity
}

\author{
Pierre Durand* Gaëtan Le Quang*
}

April 10, 2020

\begin{abstract}
Banking regulation faces multiple challenges that call for rethinking the way it is designed in order to tackle the specific risks associated with banking activities. In this paper, we argue that regulators should focus on designing strong equity requirements instead of implementing several complex rules. Such a constraint in equity is however opposed by the banking industry because of its presumed adverse impact on banks' performance. Resorting to Random Forest regressions on a large dataset of banks balance sheet variables, we show that the ratio of equity over total assets has a clear positive effect on banks' performance, as measured by the return on assets. On the contrary, the impact of this ratio on the shareholder value, as measured by the return on equity, is most of the time weakly negative. Strong equity requirements do not, therefore, impede banks' performance but do reduce the shareholder value. This may be the reason why the banking industry so fiercely opposes strong equity requirements.
\end{abstract}

Keywords: Banking regulation ; Capital requirements ; Basel III ; Random Forest regressions. JEL classification : C44, G21, G28

Acknowledgements: The authors would like to thank their colleagues from the EconomiX research centre. They are particularly grateful to Laurence Scialom and Valérie Mignon for their guidance and advice.

*EconomiX - CNRS, University of Paris Nanterre

Corresponding author: pierre(.)alexis(.)durand(@)hotmail(.)fr 


\section{Introduction}

Banking regulation proved inadequate to prevent the banking system from collapsing at the end of the 2000s. Massive public bailouts thus occurred and banking regulators began to work on a new framework meant to make it possible to contain the risk inherent to banking activities. This risk is now known as being systemic and as striking both sides of the balance sheet. Macroprudential tools - such as regulatory countercyclical buffers - and liquidity requirements - such as the Liquidity Coverage Ratio (LCR) and the Net Stable Funding Ratio (NSFR) - have therefore been put in place to tackle the threats posed by the specific nature of banking risk. In addition, bail-in instruments have been designed to prevent costly bailouts from occurring whenever a bank deemed too big to fail goes bankrupt.

Banking regulation has thus evolved after the 2007-2008 financial collapse. The macroprudential shift that began right after the crisis seems to lead banking regulation in the right direction. However, knowing that the previous financial crisis was, among other reasons, due to the very complexity of the financial system, ${ }^{1}$ it is quite surprising to notice that the regulatory framework newly designed is very complex. The first pillar of Basel III indeed states that banks have to comply with two liquidity ratios, one leverage ratio and a risk-based capital ratio. Two bail-in standards - the Total Loss Absorbing Capacity (TLAC) that concerns systemic banks and the Minimum Requirement for own funds and Eligible Liabilities (MREL) that concerns every bank located in the European Union - have additionally been put in place to protect taxpayers from bailouts. This complexity paves the way for criticism coming from the banking industry, arguing that such a multiplication of rules can only hamper banks' activity. ${ }^{2}$

The objective of this paper is to suggest that banking regulation would be better off focusing more on equity instead of relying on complex and less transparent rules. We argue that implementing a strong constraint in equity would have the advantage of being both more transparent and more efficient than the current regulatory framework. Such a constraint is strongly opposed by the banking industry that argues that it would presumably cost a lot to society as a whole because of the restrictions in bank lending that would follow. The argument here is that increasing equity requirements would necessarily augment funding costs and thus hamper banks' lending activity. As Admati et al. (2013) show, this is a fallacious argument. Those authors indeed point out that a sharp increase in equity requirements would more likely have the opposite effect. Their idea is that since increasing equity requirements decrease the risk associated with banks' activities, they can issue bonds at a lower cost and, therefore, their total funding cost could decrease instead of rising as is often argued. Gambacorta and Shin (2018) provide empirical evidence that an increase of 1 percentage point in the ratio of equity over total asset yields a decrease of 4 basis points in the cost of debt for a sample of banks located in the

\footnotetext{
${ }^{1}$ This complexity was the direct consequence of the great promotion of financial innovation during the 2000s (Brunnermeier, 2009).

${ }^{2}$ In January 2020, the French Parliament voted against the full implementation of Basel III arguing mainly that it would impede banks' activities too much.
} 
G10 countries. In other words, increasing equity requirements could decrease banks' funding cost and thus eventually improve their performance. There is therefore no economic reason to oppose to a strong increase in equity requirements.

Our paper provides empirical evidence to support this idea. To do so, we use random forest (RF) regressions on a large dataset of banks' balance sheet variables over the period 20002018 in 21 countries to assess the predictive power of a large number of variables on several measures of banks' performance. The key contribution of our paper is to show that the ratio equity over total assets $\left(\frac{\mathrm{E}}{\mathrm{TA}}\right)$ has a strong quasi-linear positive impact on banks' performance as measured by the return on average assets (ROAA). Far from impeding banks' profitability, high equity requirements could thus foster it. On the contrary, we show that the ratio $\frac{\mathrm{E}}{\mathrm{TA}}$ has a non-linear impact on the return on average equity (ROAE). In particular, when the ratio $\frac{\mathrm{E}}{\mathrm{TA}}$ is below approximately $10 \%$, the ROAE is negatively impacted by an increase in this ratio. The shareholder value is thus most of the time negatively affected by an increase in $\frac{E}{\mathrm{TA}}$, which is probably the main reason why the banking industry opposes higher constraints in equity. The main cost associated with an increase in equity requirements is, therefore, supported by shareholders (since the ROAE decreases when $\frac{\mathrm{E}}{\mathrm{TA}}$ increases) and not by other stakeholders (since the ROAA increases when $\frac{E}{T A}$ increases). This is the main insight of our paper. ${ }^{3}$

The methodological novelty introduced by the paper is the use of RF regressions to assess the impact of various variables on banks' performance. The rationale behind this approach is that it allows considering the impact of a large number of determinants and to range them according to their predictive power. Doing so we show that the ratio $\frac{\mathrm{E}}{\mathrm{TA}}$ is among the best predictors of banks' performance. Allowing for such a comprehensive dataset is one of the reasons why we chose to resort to RF regressions instead of more standard methods. Three other reasons also justify this choice. First, RF regressions do not impose to choose a specific functional form. Second, $\mathrm{RF}$ regressions incorporate both a procedure for estimating the determinants (or features) and their impact on the explained variable (or label). Third, RF regressions perform well out-ofsample (Hastie et al., 2009). In order to ensure the stability and soundness of our results, we provide several robustness checks: (i) we consider different measures of banks' performance, (ii) all results are compared to those of a Lasso model, (iii) all simple RF regressions' outcomes are compared with the mean of numerous (50 to 100) RF regressions run on random sample selection, and (iv) estimations are run on two samples.

This paper lies in the literature on the determinants of banks' performance. Part of this literature deals with the impact of capital on profitability. No consensus is however to be found. Some papers conclude on the existence of a positive relationship between capital and profitability (Berger, 1995; Iannotta et al., 2007; Lee and Hsieh, 2013). This positive relationship is explained by lower default probability and a decrease in funding costs. Other papers provide evidence of

\footnotetext{
${ }^{3}$ This is totally in line with the conclusion of Admati et al. (2013): "Most importantly, the cost to shareholders is entirely a private cost based on being able to benefit at the expense of creditors or taxpayers when there is less equity in the mix. Thus, it does not establish any social cost to increased equity requirements." (p.36).
} 
a negative relationship, justified by the existence of a "low-risk anomaly" and difficulties for high-capitalized bank to diversify their activity (Goddard et al., 2013; Baker and Wurgler, 2015). Fewer papers are dedicated to studying the impact of liquidity on profitability. On the one hand, holding liquid assets decreases the maturity mismatch and thus the liquidity risk. Banks that hold a large proportion of their asset portfolio in liquid assets thus benefit from low funding costs since they are less likely to go bankrupt, which has a positive impact on their performance (Berger and Bouwman, 2009; Bordeleau and Graham, 2010). On the other hand, liquid assets generate low returns and therefore low revenues. In this perspective, banks that hold a large amount of liquid assets are likely to perform less than banks investing in riskier assets (Goddard et al., 2013; Molyneux and Thornton, 1992). Apart from the impact of capital and of liquid assets holding on profitability, the literature focuses on other determinants of profitability such as market concentration (Bourke, 1989; Dietrich and Wanzenried, 2014; Molyneux and Thornton, 1992), cash and bank deposits (Bourke, 1989; Molyneux and Thornton, 1992), credit risks and loan loss provisions (Dietrich and Wanzenried, 2014; García-Herrero et al., 2009), tax variables (Albertazzi and Gambacorta, 2009; Chia and Whalley, 1999) and non-performing loans (García-Herrero et al., 2009). The impact of macroeconomic variables on profitability has also been assessed by many papers, for instance the impact of GDP growth rates (Bordeleau and Graham, 2010; Dietrich and Wanzenried, 2014), that of inflation (Bordeleau and Graham, 2010; Bourke, 1989; Dietrich and Wanzenried, 2014) and that of monetary policy (Borio et al., 2017).

To our knowledge, our paper is the first to resort to RF regressions to investigate the determinants of banks' performance. Doing so and as stressed above, we show that the ratio equity over total assets is one of the main predictors of the performance when measured as the ROAA, and has furthermore a linear and positive impact on it. This is a major debunking of the idea according to which designing strong equity requirements would necessarily impede banks' activity and thus have an adverse impact on society as a whole. As a consequence, this paper provides support to the definition of a strong constraint in equity instead of the multiplication of rules that could each have potentially harmful unexpected consequences.

The remainder of this paper is structured as follows. Section 2 provides a brief overview of the regulatory framework that has been put in place after the crisis and presents the tested hypothesis. The methodology is discussed in section 3. Data are presented in section 4 alongside

with some descriptive statistics. Section 5 reports the results, and robustness checks are provided in Section 6. Section 7 concludes.

\section{Regulatory framework and tested hypothesis}

This section provides an overview of the key novelties introduced by banking regulators after the crisis. Then, we formulate the hypothesis that will be tested using RF regressions. 


\subsection{A brief overview of the regulatory framework}

As already mentioned, banking regulation has been renewed after the crisis. However, in spite of the diagnosis that was formulated right after the crisis (i.e., the necessity to contain systemic risk through proper macroprudential policies), the regulatory framework that is currently implemented is somewhat disappointing (Baker, 2013). Capital requirements have indeed barely been strengthened, liquidity regulation is ill-designed, and bail-in instruments could have unexpected harmful consequences. We detail all these points here.

Capital requirements have been modified after the crisis. In particular, the definition of regulatory capital has been tightened and many hybrids that were used to be integrated in regulatory capital are now ruled out. Banks now have to hold at least $7 \%$ of their risk-weighted assets in core capital compared to $2 \%$ under Basel II. Core capital requirements have thus been strengthened. However, as Admati et al. (2013) state it, a lot more can be done in this direction. In fact, the implementation of bail-in standards in addition to the capital constraints defined in the first pillar of Basel III can be interpreted as a palliative for low core capital requirements (Persaud, 2014).

Both the TLAC and the MREL define constraints in what is called eligible liabilities. Those are financial instruments that are associated with a high loss-absorbing capacity in the event where the issuing bank goes bankrupt. Contingent convertible bonds (coco bonds) are such eligible liabilities. They are bonds that behave like regular bonds in normal times but are converted into equity whenever a pre-defined event occurs. The main purpose of such bonds is to make it possible for banks to fund themselves by issuing bonds that are cheaper than equity and to make them benefit nonetheless from a loss-absorbing capacity similar to that of equity. Coco bonds are however not a panacea. They indeed could serve as a channel through which systemic risk could materialize. For instance, Corcuera et al. (2014) show that because of the conversion risk, coco bonds exhibit a death-spiral effect. To hedge the conversion risk, coco bonds' holders may indeed short sell shares. Doing so they may find themselves in a position of selling shares whose price is decreasing and, therefore, they may contribute actively to the materialization of the conversion risk. By hedging the conversion risk, investors thus make it more likely. Hence the spiral effect. Bologna et al. (2018) provide empirical evidence that shows how contagion can spread in the coco bonds market. Using two stress episodes that affected the European coco bonds market in 2016, the authors exhibit a significant coco bonds-specific contagion that can be the consequence of the reassessment by investors of coco bonds' riskiness. Coco bonds are thus complex financial instruments that could eventually act as a channel through which systemic risk propagates. Expectations of conversions could indeed nourish self-fulfilling panic sales of coco bonds and thus precipitate a market-wide panic that could spread to the whole financial system (Le Quang, 2019). It is therefore of the utmost

importance to keep in mind that one of the reasons why the global financial crisis was so severe was because the systemic risk associated with securitized products had been largely overlooked. 
The current will to ensure financial stability through complex financial instruments, such as coco bonds, thus appears as a dangerous oversight of history. This is one of the reasons why contingent capital must not be used as a palliative for equity (Admati et al., 2013).

Liquidity regulation has been implemented through two different rules: the LCR and the NSFR. The LCR states that banks need to hold enough high quality liquid assets (HQLA) to withstand a liquidity crisis lasting 30 days. In other words, banks need to hold enough liquid assets to cope with their short-term liquidity needs. The NSFR states that banks' illiquid assets need to be funded through stable funding instruments. The first question that arises when looking at current liquidity regulation is why two ratios instead of one. Having a closer look at them, we notice that the two ratios are in fact redundant. Let us demonstrate it through an example. ${ }^{4}$ Consider a bank whose asset portfolio is made both of liquid and illiquid assets that are funded through runnable and not-runnable liabilities. The balance sheet of the bank is thus as follows:

\begin{tabular}{|cc|}
\hline Asset & Liability \\
\hline Liquid assets $(L A)$ & Runnable liabilities $(R L)$ \\
Illiquid assets $(I A)$ & Not-runnable liabilities $(N R L)$ \\
\hline
\end{tabular}

The LCR is met whenever $L A>R L \Longleftrightarrow L A-R L>0$. The NSFR is met whenever $N R L>I A \Longleftrightarrow N R L-I A>0$. The balance sheet identity states that $L A+I A=N R L+R L$. In other words, we have $L A-R L=N R L-I A$. As a consequence, whenever the LCR is binding, the NSFR is binding too and vice versa. The two ratios are thus likely to be redundant since when one is binding, the other is necessarily binding too. Instead of two ratios, liquidity regulation would thus be better off defining only one ratio. This would be a first step towards reducing the complexity of the regulatory framework. Which ratio should then be ruled out and which should remain? The difference between the two ratios is the side of the balance sheet on which they focus: the LCR focuses on the asset side, while the NSFR focuses on the liability side. We believe for two reasons that the perspective that should be adopted is that of the NSFR. The first reason lies in the very definition of the LCR. It is defined as the ratio of HQLA over runnable liabilities. The problem is that the very fact of defining some assets as HQLA could make those assets illiquid in the event of a crisis. This idea is what has been coined as the Goodhart's law based on a quotation from a paper by Charles Goodhart according to which "any observed statistical regularity will tend to collapse once pressure is placed upon it for control purposes" (Goodhart, 1975). Gambling financial stability on the definition of liquid assets is therefore dangerous. AAA securitized products were indeed deemed rather liquid before their market freezed. The second reason echoes the current concern of prudential regulators to take climate change into account (Bolton et al., 2020). To do so, financial regulation has to incentivize banks

\footnotetext{
${ }^{4}$ The reasoning comes from Bolton et al. (2019).
} 
to invest in green assets in order to fill the green investment gap. Those assets are in general long-term assets. By constraining banks to invest in short-term liquid assets, the LCR could thus deter banks from investing in green assets. Consequently, such liquidity requirements are expected to have a negative impact on the access to finance of low-carbon sectors (Campiglio, 2016). Liquidity regulation should then focus more on the liability side than on the asset side of the balance sheet.

To summarize, banking regulation has evolved after the great financial crisis to tackle the new risks that materialized at the end of the 2000s. However, the current regulatory framework suffers from obvious flaws. In particular, too many rules are being implemented and none is perfectly well-designed. We think that they could all be replaced by a unique strong equity constraint that would be both more transparent and efficient. In addition, we think that such a constraint would not impede banks' activities. This twofold hypothesis is discussed in more detail in the next section.

\section{$2.2 \quad$ Tested hypothesis}

Higher equity requirements could achieve the objective of all the rules that have been presented in the previous section. Equity is indeed the best funding instrument to absorb losses and thus to make sure that failing banks will be bailed-in instead of bailed-out. As Admati et al. (2013) note it, equity indeed dominates convertible debt in this matter. Liquidity regulation aims at ensuring the consistency of banks' balance sheet by limiting maturity mismatch. Before the crisis, banks indeed strongly relied on very short-term financial instruments to fund longerterm assets, which exposed them to short-term liquidity risks (Acharya et al., 2011; Morris and Shin, 2016). Defining higher equity requirements would probably make it possible to reduce the maturity mismatch and thus to reduce the exposure of banks to liquidity risks without relying on a questionable definition of which assets are deemed highly liquid and which are not. In addition, it could incentivize banks to invest more in green assets and thus favor the transition towards a greener economy: banks that rely more on equity face a lower liquidity risk and are, therefore, more able to invest in longer term assets.

In this perspective, strong equity requirements appear as a better solution than the definition of liquidity ratios to ensure financial stability and as a better solution than bail-in standards to protect taxpayers from costly bailouts. Such requirements are moreover expected to have a positive impact on the funding of green projects. In this paper, we start from the idea that equity indeed performs better than both bail-in standards and liquidity ratios in fulfilling their goals.

Starting from this idea, we inquire whether the arguments opposed by the banking industry to higher equity requirements are justified or not. The main argument against such requirements is that they would have a negative impact on the ability of banks to conduct their activities by impeding their performance. We aim at providing empirical evidence that the relationship could 
actually be the reverse. Since higher equity requirements reduce the probability that banks end up bankrupting, it is expected that better-capitalized banks are able to issue bonds at a lower cost. All in all the total funding cost of banks could decrease and their profitability thus increase. If this is indeed the case, nothing opposes the definition of higher equity requirements. This is the hypothesis that is tested in this paper. To do so, we resort to RF regressions, which are presented in the next section.

\section{Random forest regressions}

Tree-based models and random forest regressions.

The RF methodology (Breiman, 2001) is a supervised statistical learning method that allows to consider a large number of explanatory variables, to capture non-linearities, interactions between variables and perform well out-of-sample (Hastie et al., 2009). It consists in a bootstrap aggregation of decision trees. The difference with bagging techniques comes from the fact that it averages responses of trees built on a randomly selected sample among the training data and features. Doing so, RF regressions' performance is often close to those of boosting (Hastie et al., 2009).

Decision trees are built via recursive binary partition of the space of explanatory variables into $M$ regions (or leaves) : $\left\{R_{m}, m \in \llbracket 1, M \rrbracket\right\}$. Then, an output value is predicted through a simple model. At each split of features space, we choose the variable $X_{j}$ for which the split $s$ gives the best fit of the output variable (or label). Once the tree is built, the label is predicted by a constant value in each final region:

$$
f(x)=\sum_{m=1}^{M} c_{m} I\left(x \in R_{m}\right),
$$

where $x$ is the explanatory variable, $I$ is an indicative function that scores 1 when $x \in R_{m}$, $M$ denotes the number of final leaves, and $c_{m}$ stands for the predicted value of the explained variable $y$, in region $m$. Therefore, this method is a non-parametric estimation of the unknown function $f$. This function defines the true model: $y=f(x)+\epsilon$, where $\epsilon$ designates the error term.

Shallow trees with large number of observations per leave are likely to have poor prediction performance, while excessively deep trees with few observations per final regions will lead to overfitting issues and bad out-of-sample forecasting. This governs the determination of the decision trees' parameters: depth and number of observations per leave. The last parameter to establish is the number of trees in the forest. There are some debates on the optimal value for this parameter (and the very existence of an optimum). Hastie et al. (2009) suggest that the error of the model generally decreases and converges as the number of trees grows. From this perspective, the right number of trees corresponds to the moment where the error does not 
decrease below a certain threshold. Oshiro et al. (2012) show that, in some cases, the convergence of errors is not ensured. To avoid any risks in our empirical investigation, we determine simultaneously all three parameters: $\left(D_{\max }, O_{\min }, T_{\text {trees }}\right)$, respectively the maximum depth of trees, the minimum number of observations per final region, and the number of trees. To do so, we compare RF regressions out-of-sample scores making those three parameters vary.

RF interpretation.

As the number of features increases, visualization becomes more complex. However, it remains central since it often appears that numerous variables are irrelevant. This part is managed by the calculation of predictors' relative importance (Breiman et al., 1984; Hastie et al., 2009). Moreover, some techniques, known as Quantitative Input Influence, make it possible to visualize features' marginal impact on labels. Precisely, we use both Partial Dependence Plots (Friedman, 2000; Hastie et al., 2009) and Accumulated Local Effects (Datta et al., 2016).

In order to assess variables' importance, we rely on a generalization of Breiman et al. (1984)'s measure of relevance for a single tree. It averages the sum of improvements across all trees, given by each variable when it is chosen as the splitting one. This measure attributes a standardized score to all features giving their determining power on labels.

A Partial Dependence Plot (PDP) is then built to provide a summary of the output dependence on the joint values of the inputs (Friedman, 2000; Hastie et al., 2009). PDPs average Individual Conditional Effects (ICE) over all individual. Considering the $i$-th individual and variable $X_{j}$, the ICE corresponds to the predictions of the model making vary $X_{j}$ from its minimum to its maximum with step $k$, and fixing all the other variables to their level took for the $i$-th individual. One of the most important issues in PDPs is that it assumes independence between the predictor for which the partial dependence is computed and the other ones. Besides, making $X_{j}$ vary across all its distribution creates the risk to overfit regions with almost no data. In order to overcome this issue, we rely on Accumulated Local Effect (ALE).

$\mathrm{ALE}^{5}$ (Datta et al., 2016) also proposes to calculate the marginal effect of $X_{j}$. The main differences with PDP can be summarized as follows: ALE is unbiased even when features are correlated, it marginalizes over probable combinations of features, and it is faster to compute. Technically, ALE bases its calculation on existing data intervals for explanatory variables. Moreover, ALE averages the changes of predictions, not the predictions itself. Another significant difference with PDP is that ALE accumulates the local gradients over the range of features $S$, giving their effect on the predicted variable. Finally, ALE method is centered so that the average effect is zero. In practice, ALE for one given feature is computed, dividing it into many intervals, and computing the differences in the predictions. ${ }^{6}$ The internal calculation of ALE adds up the impacts of all individuals within an interval that appears as a neighbourhood.

\footnotetext{
${ }^{5}$ Note that the package we use includes Monte-Carlo simulations.

${ }^{6}$ This approximates the local gradients and allows us to compute ALE using RF regressions.
} 


\section{Data and descriptive statistics}

\subsection{Data}

The objective of our empirical strategy is to determine what are the main predictors of banks' performance to decide whether or not increasing equity requirements would have the negative impact put forward by the banking industry to oppose them. To do so, we selected four variables to account for banks' performance: the return on average assets (ROAA) (Berger et al., 1995; Osborne et al., 2012; Tran et al., 2016; Xu et al., 2019), the return on average equity (ROAE) (Berger, 1995; Osborne et al., 2012; Distinguin et al., 2013; Tran et al., 2016; Xu et al., 2019), the operating profit before tax to total assets (OPTA) (Xu et al., 2019), ${ }^{7}$ and the net interest margin (NIM) (Albertazzi and Gambacorta, 2009; Xu et al., 2019).

Explanatory variables and the corresponding data sources are presented in Appendix A. Among those variables, three are worth pointing out. The first one is equity over total assets $\left(\frac{\mathrm{E}}{\mathrm{TA}}\right)$. This variable accounts for the proportion of the asset portfolio that is funded through equity. The higher the ratio, the better the bank is capitalized. The main purpose of our empirical strategy is to assess to what extent this ratio impacts banks' performance and in which direction. Higher equity requirements would indeed translate into higher values of this ratio. The other variables worth pointing out are the total capital ratio (TCR) and the liquidity coverage ratio (LCR). They account for prudential regulation as it is currently implemented. Determining their impact on banks' performance would allow to disentangle which part of banking regulation (if any) does impede banks' activities, as it is argued by the banking industry.

We consider two different databases that both consist in banks' balance sheet variables from twenty one countries ${ }^{8}$ selected for their economic proximity, the fact that Basel III is nearly at the same stage of implementation in these jurisdictions, and the availability of data. The difference between the two databases lies in whether they include the LCR or not. Data are annual and come from the FitchConnect database.

The main constraint associated with the implementation of RF regressions is that they cannot be carried out successfully if the database contains any missing value. Taking this constraint into account, our two samples are as follows: the sample that includes the LCR among the explanatory variables comprises 63 variables for 1221 observations, ${ }^{9}$ while the sample without the LCR includes 62 variables for 15310 observations. Rearranging the databases to remove

\footnotetext{
${ }^{7}$ Note that the usual variable here is Operating Profit in level. A size effect being strongly detected in our regressions, we controlled for this bias dividing Operating Profit by Total Assets.

${ }^{8}$ Belgium, Canada, China, Denmark, Finland, France, Germany, Ireland, Italy, Japan, Luxembourg, the Netherlands, Norway, Poland, Portugal, Singapore, Spain, Sweden, Switzerland, the United Kingdom and the United States.

${ }^{9}$ An observation is defined as a bank for a given year. The number of banks evolves through the period we consider. See Appendix B for more details on the number of banks.
} 
twin variables (i.e,. those with a very similar definition and measurement), we kept respectively 46 and 45 variables. ${ }^{10}$ Note that since the LCR is specific to Basel III, the dataset that contains it covers only the 2012-2018 period, whereas the other dataset goes from 2000 to 2018.

The critical difference in the number of observations when forcing the dataset to contain the LCR comes from the fact that FitchConnect does not disclose any data for this regulatory ratio concerning US banks.

\subsection{Descriptive statistics}

Before presenting the results of RF regressions, we display some descriptive statistics on the explained variables' distribution and the features correlations. Figure 1 shows the distribution of our four profitability variables. As can be seen, the output variables are highly concentrated around their respective average. All four variables also display some outliers, ${ }^{11}$ but RF regressions are robust to the presence of such observations. Indeed, each tree is built on a new randomly selected sample of features and data. Therefore, among the entire forest, outliers are taken into account. ${ }^{12}$ As mentioned earlier, Partial Dependence Plots' calculation can be biased when features are correlated. As shown by Figure 2, which displays the linear correlations between all explanatory variables, high correlation exists for some features. Indeed, the sample of variables going from Business Volume to Other Assets displays high correlation levels with numerous other inputs. The use of ALE in order to support PDPs' results is thus relevant.

Figure 1 - Profitability variables' distribution
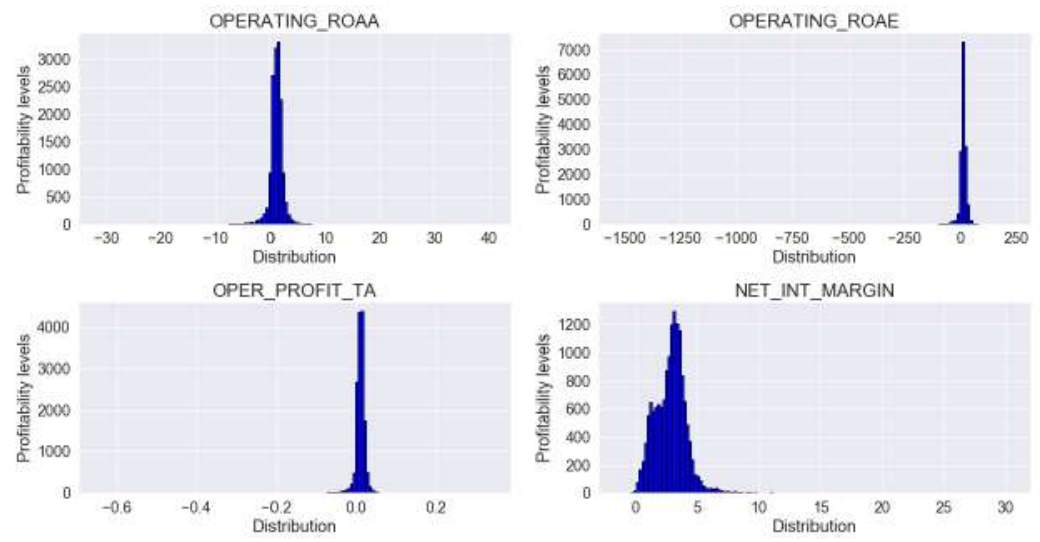

Source: Authors' calculations from FitchConnect data.

\footnotetext{
${ }^{10}$ We also constrained the dataset to include some accounting and macroeconomic variables identified from the literature.

${ }^{11}$ Those outliers are not apparent being too few.

${ }^{12}$ To ensure that no bias is created by those high values, we constrained the sample selection of the robustness check by averaging results over $100 \mathrm{RF}$ regressions. To do so, we forced the model to select data from all deciles. We controlled the sampling comparing the new and old distributions' first two moments. The goal of this robustness check is also to control for outliers in Lasso regressions.
} 
Figure 2 - Linear correlation between features

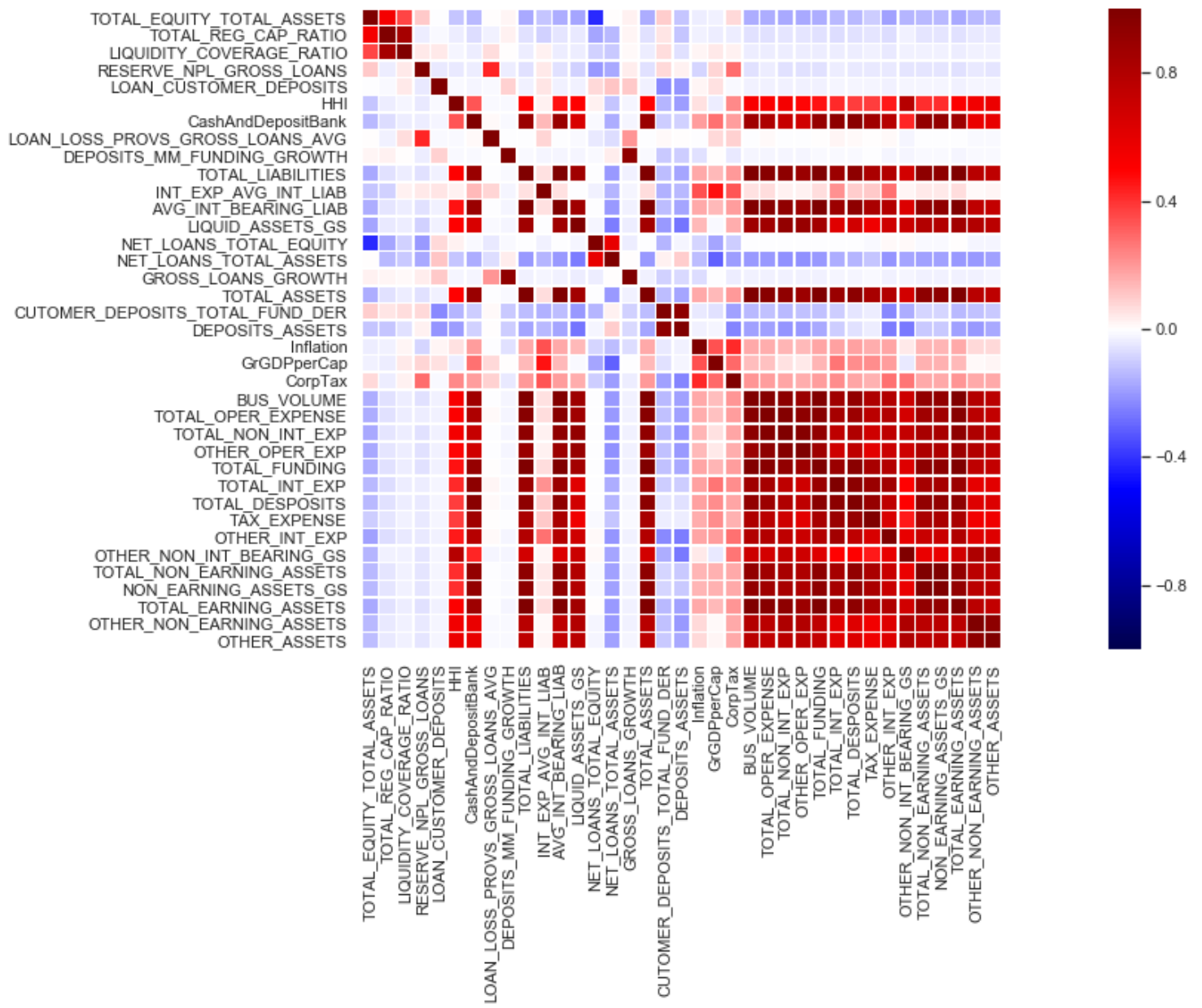

Source: Authors' calculations from FitchConnect data.

\section{$5 \quad$ Results of $\mathrm{RF}$ regressions}

In this section, we present the results of RF regressions run on the sample that comprises the LCR when the ROAA and the ROAE are the dependent variables. Results concerning the OPTA and the NIM are in the Appendix C.1 alongside with those run on the other sample. We first check the quality of the model by comparing its performance (as measured by the $R^{2}$ ) both in- and out-of-sample to those of the Lasso model ${ }^{13}$. We then present the main results regarding the ROAA and the ROAE.

\footnotetext{
${ }^{13}$ The Lasso model (Tibshirani, 1996) consists in a shrinkage linear method for regression problem. It works imposing a penalty on the regression coefficients' size. Doing so, the model is forced to give importance to the coefficients that increase the most its quality.
} 


\subsection{RF versus Lasso model}

A standard way to deal with a large number of explanatory variables is to resort to the Lasso model. Lasso indeed makes it possible to select among a great amount of explanatory variables those which are worth taking into account and those which are not. Inquiring what are the main determinants of banks' performance is therefore possible resorting to a Lasso model. However, in our case, RF regressions outperform the Lasso model. Running Lasso regressions on our dataset, we indeed notice that the $R^{2}$ of the RF model is always above that of Lasso models, whatever the dependent variable (Table 1). What is worth noting is that RF regression out-of-sample's $R^{2}$ is superior to those of Lasso model in-sample.

Table 1 - Model's quality: RF versus Lasso

(a) ROAA as the dependent variable

\begin{tabular}{c|ccc}
\hline \hline \multirow{2}{*}{ Sample } & \multicolumn{3}{|c}{ Models } \\
\cline { 2 - 4 } & RF & Lasso (AIC) & Lasso (BIC) \\
\hline In-sample & 0.86 & 0.31 & 0.29 \\
Out-of-sample & 0.43 & 0.15 & 0.13 \\
\hline \hline
\end{tabular}

(b) ROAE as the dependent variable

\begin{tabular}{c|ccc}
\hline \hline \multirow{2}{*}{ Sample } & \multicolumn{3}{|c}{ Models } \\
\cline { 2 - 4 } & RF & Lasso (AIC) & Lasso (BIC) \\
\hline In-sample & 0.81 & 0.24 & 0.21 \\
Out-of-sample & 0.56 & 0.09 & 0.10 \\
\hline \hline
\end{tabular}

Source: Authors' calculations. The table shows the coefficient of determination $\left(R^{2}\right)$ scores. In the Lasso model, variables selection is done using both the Akaike information criterion (AIC) and the Bayes information criterion (BIC).

\subsection{When $\frac{\mathrm{E}}{\mathrm{TA}}$ increases banks' profitability (ROAA)...}

We report here the results of RF regressions when ROAA is the dependent variable. Figure 3 presents the importance of each explanatory variable in predicting ROAA. Few variables are identified as being strong determinants of bank activity's profitability. The ratio $\frac{\mathrm{E}}{\mathrm{TA}}$ is one of them, taking the fourth position of most important predictors. TCR is also associated with a great predictive power on ROAA. On the contrary, LCR is a poor predictor of ROAA and is therefore expected to have a weak impact. 
Figure 3 - Predictive power of each variable on ROAA

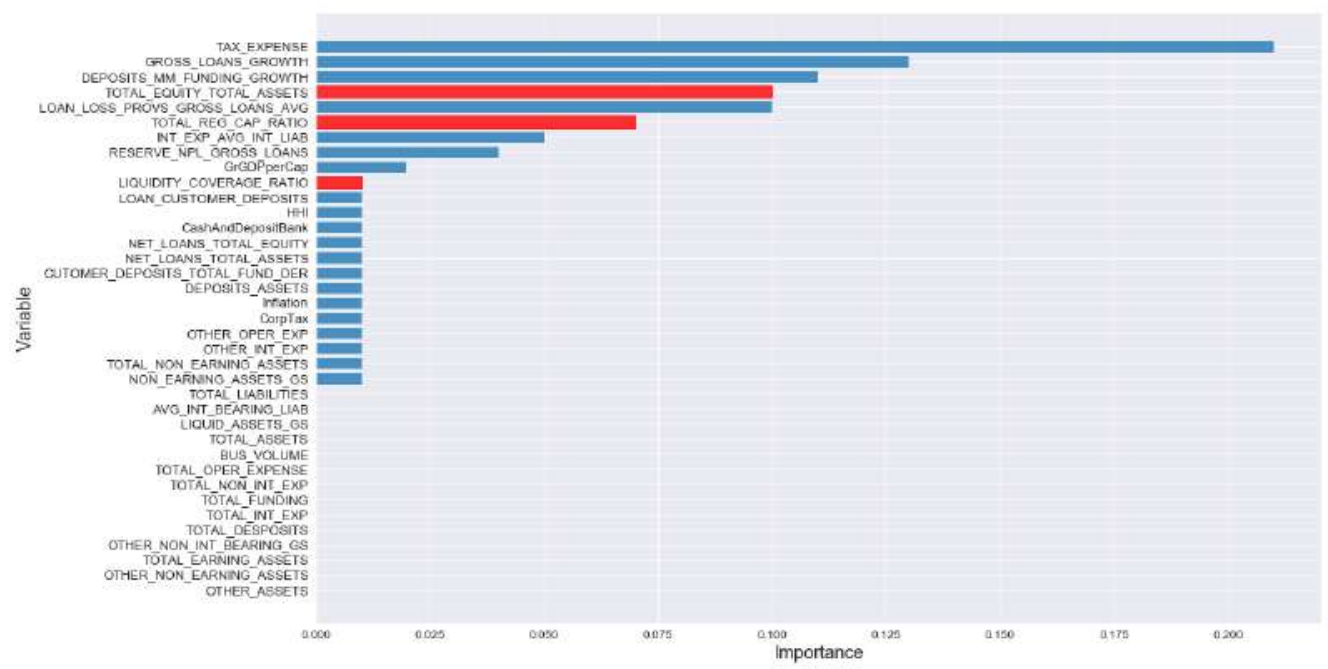

Source: Authors' calculations from FitchConnect data.

To determine in which direction goes the effect of the explanatory variables on ROAA, we use the PDPs and the ALEs. Results regarding the impact of $\frac{\mathrm{E}}{\mathrm{TA}}$ on ROAA are shown in Figure 4.

Figure 4 - Marginal impact of $\frac{\mathrm{E}}{\mathrm{TA}}$ on ROAA

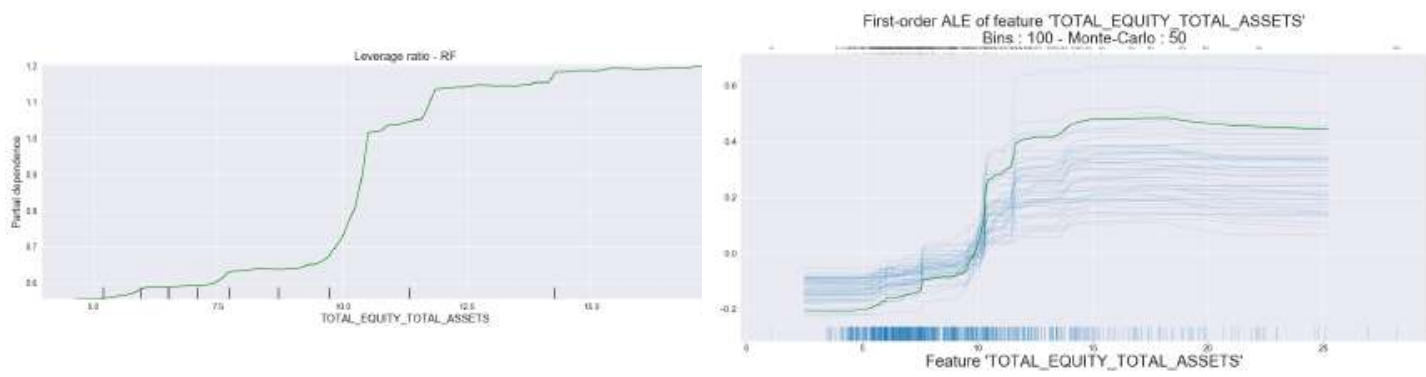

Source: Authors' calculations from FitchConnect data. The left plot displays the PDP of $\frac{E}{\mathrm{TA}}$, while the right plot shows the ALE. The distribution of $\frac{\mathrm{E}}{\mathrm{TA}}$ is reported on the $\mathrm{x}$-axes (deciles and percentiles are displayed for, respectively, PDP and ALE).

We notice that $\frac{\mathrm{E}}{\mathrm{TA}}$ has a marginal positive and quasi-linear impact on ROAA. No matter the initial value of the ratio equity over total assets, increasing equity requirements would therefore have a positive impact on the performance of banks as measured by the ROAA. Higher values of $\frac{\mathrm{E}}{\mathrm{TA}}$ are associated with lower probabilities of default and therefore with lower funding costs. Banks whose funding structure strongly relies on equity thus face low funding costs, which allow them to perform well. In sum, looking at the impact of the ratio equity over total assets on banks' performance does not support the view according to which banking regulation hampers banks' activities. Let us consider the impact of regulatory variables (TCR and LCR) to assess 
whether this view can however be defended. Results are displayed in Figure 5.

Figure 5 - Marginal impacts of TCR and LCR on ROAA
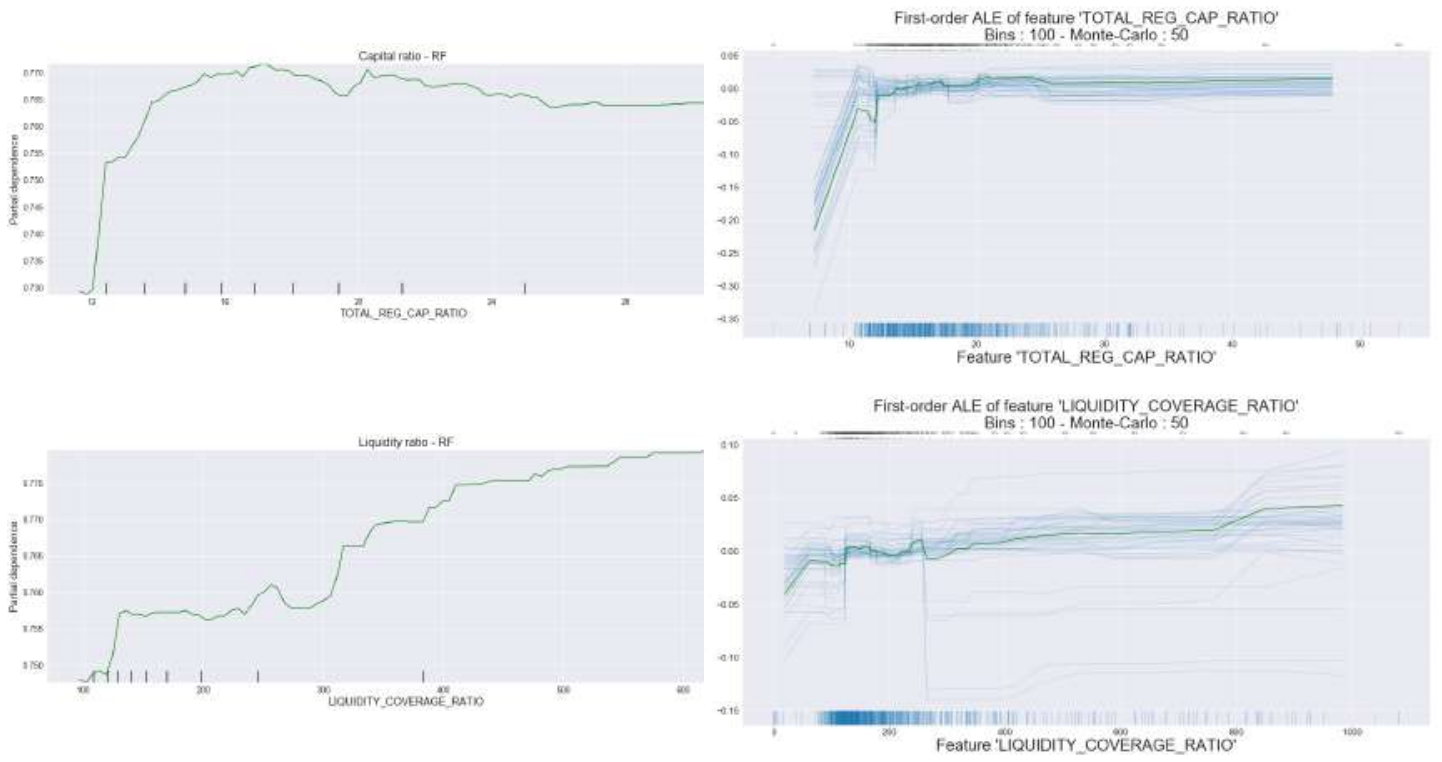

Source: Authors' calculations from FitchConnect data. The upper plots display the PDP (left plot) and the ALE (right plot) of TCR, while the lower plots show the PDP (left plot) and the ALE (right plot) for LCR. The distributions of TCR and LCR are reported on the x-axes (deciles and percentiles are displayed for, respectively, PDP and ALE).

TCR has a non-linear impact on ROAA. Below a threshold value of approximately $16 \%$, TCR has a positive impact on ROAA, while the effect is weakly negative (or even nil) for values of TCR lying above this threshold value. The idea according to which capital regulation could eventually have a negative impact on banks' performance seems to hold only for high capital ratios. ${ }^{14}$ The marginal impact of LCR on ROAA is weakly positive. This is all the more true since we have seen that LCR takes the tenth place among ROAA's predictors.

TCR and $\frac{E}{T A}$ do not have the same impact on ROAA: the impact of TCR is strongly nonlinear, while that of $\frac{\mathrm{E}}{\mathrm{TA}}$ is quasi-linear. That is quite surprising since those two variables both account for banks' capitalization. Recall however that TCR is defined as the ratio of regulatory capital (which includes both Tier 1 capital and Tier 2) over risk-weighted assets, while $\frac{\mathrm{E}}{\mathrm{TA}}$ is the simplest capital ratio possible: the ratio of equity over total assets. What is thus to be learned from the results presented so far is that a simple capital regulation (based on a simple definition of capital and risk) never impedes banks' performance, while the sophisticated Basel III ratio does so for capital ratios above a certain threshold.

Figure 6 presents the effect of the interaction between $\frac{\mathrm{E}}{\mathrm{TA}}$ and the other regulatory variables

\footnotetext{
${ }^{14}$ I.e, for values above $16 \%$ which is higher than the sum of all capital requirements combined.
} 
(TCR and LCR) on ROAA. As for the marginal impact of each of these labels, we resort here to both PDPs and ALEs. ${ }^{15}$ As was expected from Figure 3, the impact of $\frac{\mathrm{E}}{\mathrm{TA}}$ on ROAA is far stronger than those of TCR and LCR. Having for instance a look at the right plots, we indeed notice that the impact of the interaction between $\frac{\mathrm{E}}{\mathrm{TA}}$ and TCR on ROAA is entirely driven by $\frac{\mathrm{E}}{\mathrm{TA}}$. The same goes for the interaction between $\frac{\mathrm{E}}{\mathrm{TA}}$ and LCR.

Figure 6 - Impact of the interaction between $\frac{\mathrm{E}}{\mathrm{TA}}$ and regulatory variables on ROAA

(a) Two-ways PDPs of LCR with $\frac{E}{\mathrm{TA}}$, TCR with $\frac{\mathrm{E}}{\mathrm{TA}}$
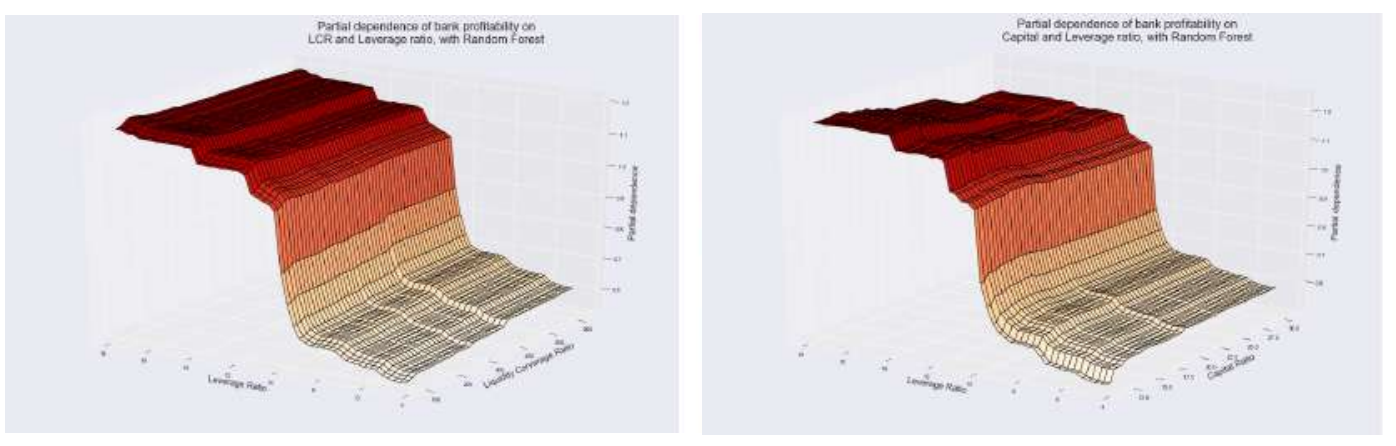

(b) Two-ways ALEs of LCR with $\frac{\mathrm{E}}{\mathrm{TA}}$, TCR with $\frac{\mathrm{E}}{\mathrm{TA}}$
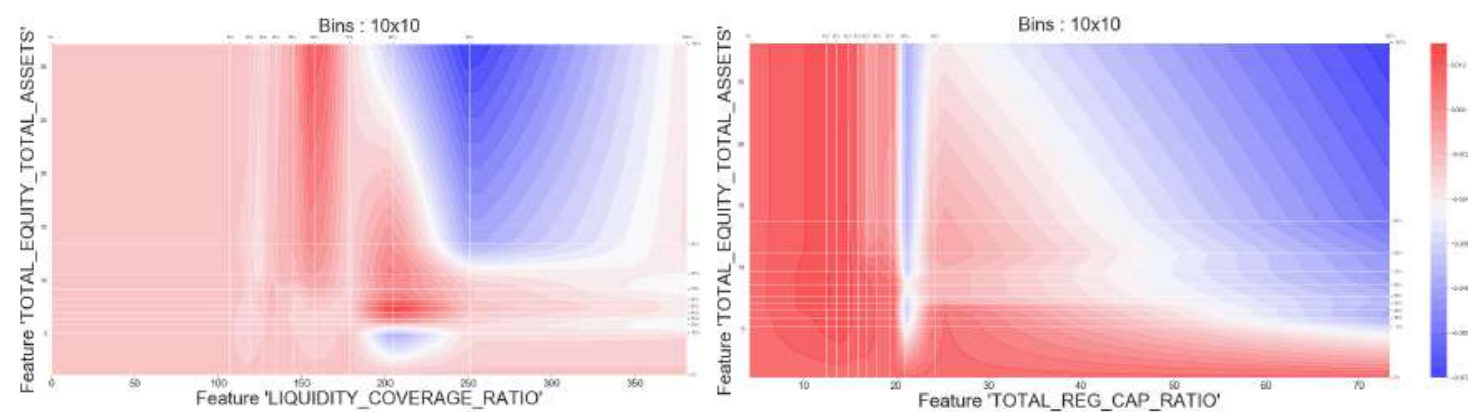

Source: Authors' calculations from FitchConnect data. The left plots display the marginal impact of the interaction between $\frac{\mathrm{E}}{\mathrm{TA}}$ and LCR on ROAA, while the right plots show the marginal impact of the interaction between $\frac{\mathrm{E}}{\mathrm{TA}}$ and TCR on ROAA.

To summarize, $\frac{\mathrm{E}}{\mathrm{TA}}$ has a strong and quasi-linear positive effect on ROAA. On the contrary, regulatory variables have a weaker impact on ROAA and are thus less convincing determinants of banks' performance. The so-called negative impact of capital regulation on banks' activities is therefore likely to be very small when capital regulation is implemented through sophisticated ratios (such as TCR) and non-existent when it is designed as a much simpler ratio (such as $\frac{E}{T A}$ ). Finally, as shown in Figure 6, an optimal combination of LCR (or TCR) and $\frac{E}{T A}$ having a strong positive impact on ROAA and allowing compliance with regulatory requirements, can always be found.

\footnotetext{
${ }^{15}$ As shown in Figure 2, those three regulatory variables are correlated with each-others. Therefore the use of ALEs is more relevant.
} 
Those results are supported by Lasso regressions run on the same sample (Table 2). The coefficient associated with the variable $\frac{\mathrm{E}}{\mathrm{TA}}$ is always significant and positive, while TCR and LCR are in both cases excluded from the model when variables' selection is done thanks to the BIC. When the AIC is used, the impact of TCR on ROAA is negative, which means that increasing TCR is expected to have a negative effect on banks' performance as measured by the ROAA. Once again, it is thus not capital per se that plays a negative role on banks' performance, but the complexity of the capital ratio (TCR versus $\frac{\mathrm{E}}{\mathrm{TA}}$ ). As for the impact of LCR on ROAA, it is here also very weak.

Table 2 - Lasso regressions (ROAA as the dependent variable)

\begin{tabular}{c|cc}
\hline \hline \multirow{2}{*}{ Variable } & \multicolumn{2}{|c}{ Models } \\
\cline { 2 - 3 } & Lasso (AIC) & Lasso (BIC) \\
\hline$\frac{\mathrm{E}}{\mathrm{TA}}$ & 0.01169 & 0.0094 \\
TCR & -0.0023 & 0 \\
LCR & $3.04 \mathrm{e}-05$ & 0 \\
\hline \hline
\end{tabular}

Source: Authors' calculations. ROAA is the dependent variable. Variables selection is done using both the Akaike information criterion (AIC) and the Bayes information criterion (BIC). A coefficient equal to 0 means that the variable has been excluded.

\section{$5.3 \quad$... but has a negative marginal impact on shareholder value (ROAE)}

In the previous section, we presented results supporting the idea that stronger equity requirements could have a positive impact on banks' performance when measured as the ROAA. This is in contradiction with the common wisdom, as put forward by the banking industry to oppose such strengthening of capital regulation. In this section, we resort to another measure of banks' performance (the ROAE) to try to make sense of this paradox. Figure 7 displays the predictive power of the explanatory variables on ROAE, in the RF regression. 
Figure 7 - Predictive power of each variable on ROAE

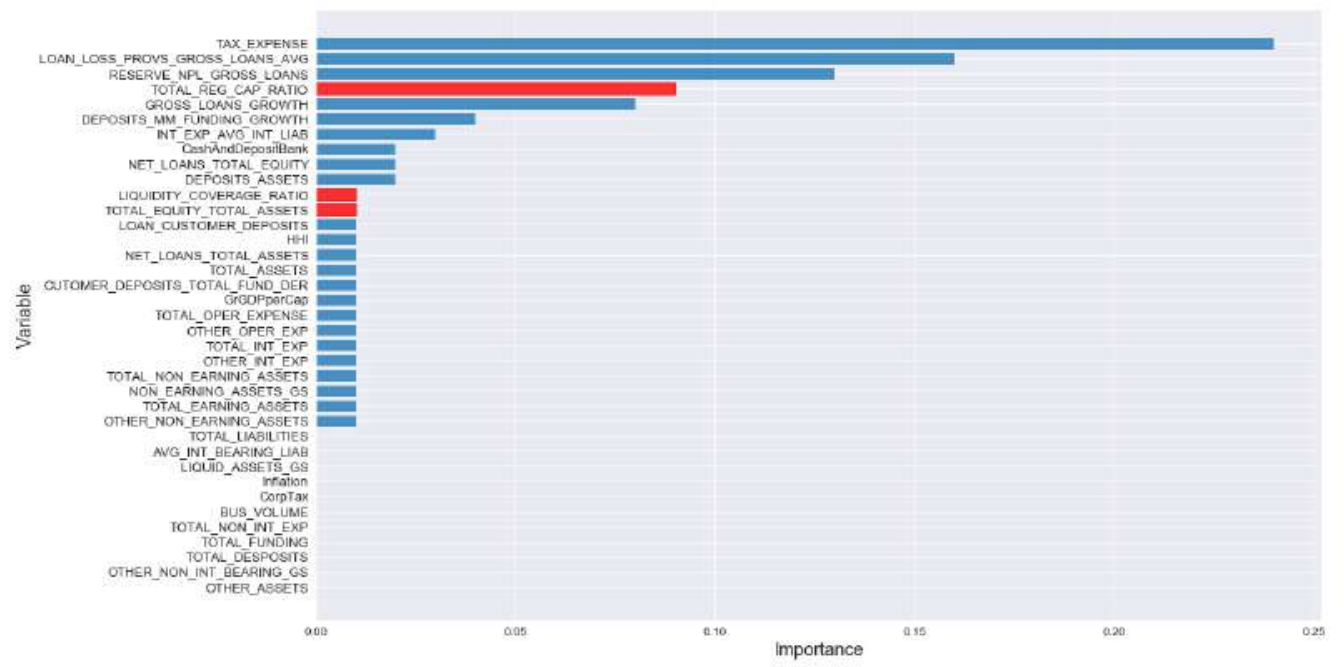

Source: Authors' calculations from FitchConnect data.

Here, TCR remains a strong determinant of profitability as measured by ROAE since it takes the fourth position among most important labels. On the contrary, $\frac{E}{T A}$ and LCR are both weak determinants of ROAE. Turning to the marginal impact of $\frac{\mathrm{E}}{\mathrm{TA}}$ on ROAE (Figure 8), we notice that increasing the value of this ratio is expected to have a negative impact on ROAE for values of this ratio below approximately $11 \%$. For values of $\frac{\mathrm{E}}{\mathrm{TA}}$ above this threshold, the relationship is the other way round. Given that the majority of the banks in our sample lie before the value of $\frac{\mathrm{E}}{\mathrm{TA}}$ for which its impact on ROAE is positive (see the distribution on the $\mathrm{x}$-axes), the impact of stronger equity requirements on the shareholder value is expected to be negative in the majority of cases. Having a closer look at the PDP (left plot in Figure 8), we indeed notice that $80 \%$ of the distribution lies in an area where the impact of $\frac{\mathrm{E}}{\mathrm{TA}}$ on ROAA is strongly negative or close to zero. If banks seek to maximize their shareholder value, it is therefore in their interest to oppose stronger equity requirements.

Figure 8 - Marginal impact of $\frac{\mathrm{E}}{\mathrm{TA}}$ on ROAE

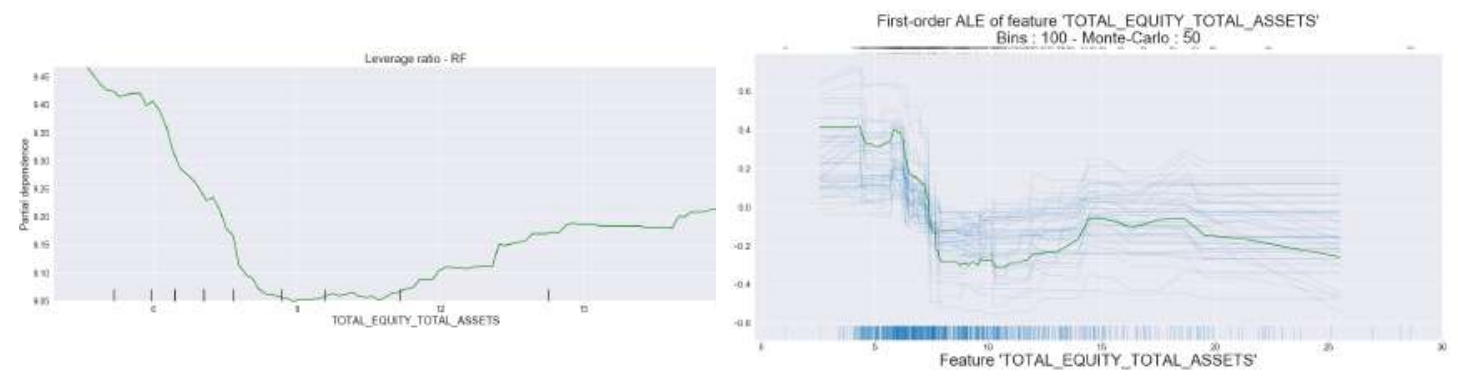

Source: Authors' calculations from FitchConnect data. The left plot displays the PDP of $\frac{\mathrm{E}}{\mathrm{TA}}$, while the right plot shows the ALE. The distribution of $\frac{\mathrm{E}}{\mathrm{TA}}$ is reported on the x-axes (deciles and percentiles are displayed for, respectively, PDP and ALE). 
Marginal impacts of TCR and LCR on ROAE are roughly the same as those on ROAA. Results are shown in Figure 9. TCR has a non-linear effect on ROAE: a positive impact below a threshold value of $16 \%$ and a negative or null impact above it. LCR has a positive impact.

Figure 9 - Marginal impacts of TCR and LCR on ROAE
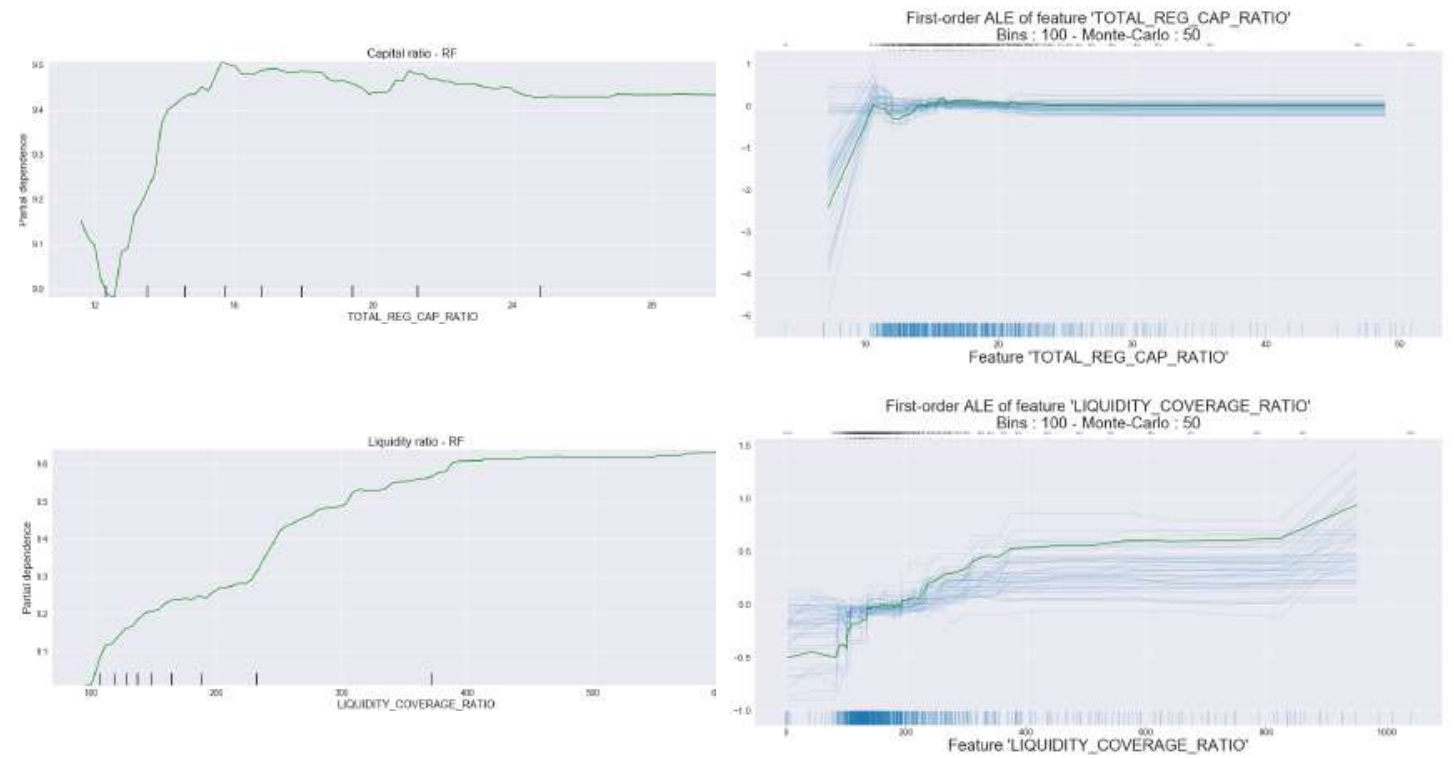

Source: Authors' calculations from FitchConnect data. The upper plots display the PDP (left plot) and the ALE (right plot) of TCR, while the lower plots show the PDP (left plot) and the ALE (right plot) for LCR. The distributions of TCR and LCR are reported on the x-axes (deciles and percentiles are displayed for, respectively, PDP and ALE).

When we have a look at the impact of the interaction between $\frac{\mathrm{E}}{\mathrm{TA}}$ and the regulatory variables on ROAE (Figure 10), we notice that it is in both cases mainly driven by $\frac{\mathrm{E}}{\mathrm{TA}}$. If banks want to maximize their ROAE, their best interest is to lobby for the implementation of a complex capital ratio instead of a simple leverage ratio. This is precisely the current shape of capital regulation: it is mostly designed around a complex capital ratio (which negative impact on ROAE is limited) while the regulatory leverage ratio is set at a very low level. 
Figure 10 - Impact of the interaction between $\frac{\mathrm{E}}{\mathrm{TA}}$ and regulatory variables on ROAE

(a) Two-ways ALEs of LCR with $\frac{E}{T A}$, TCR with $\frac{\mathrm{E}}{\mathrm{TA}}$
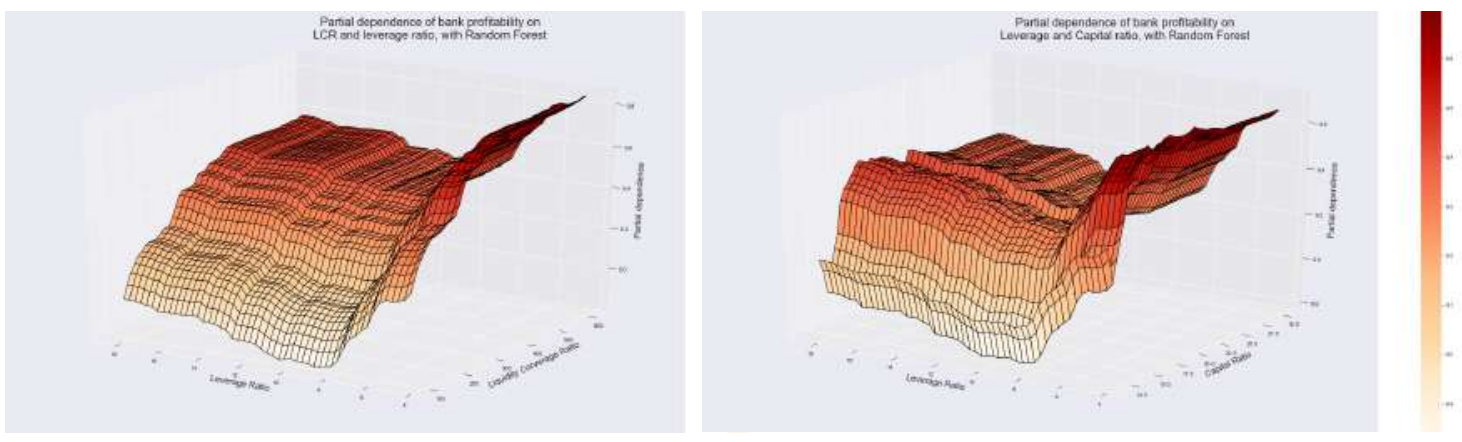

(b) Two-ways ALEs of LCR with $\frac{E}{T A}$, TCR with $\frac{E}{\text { TA }}$
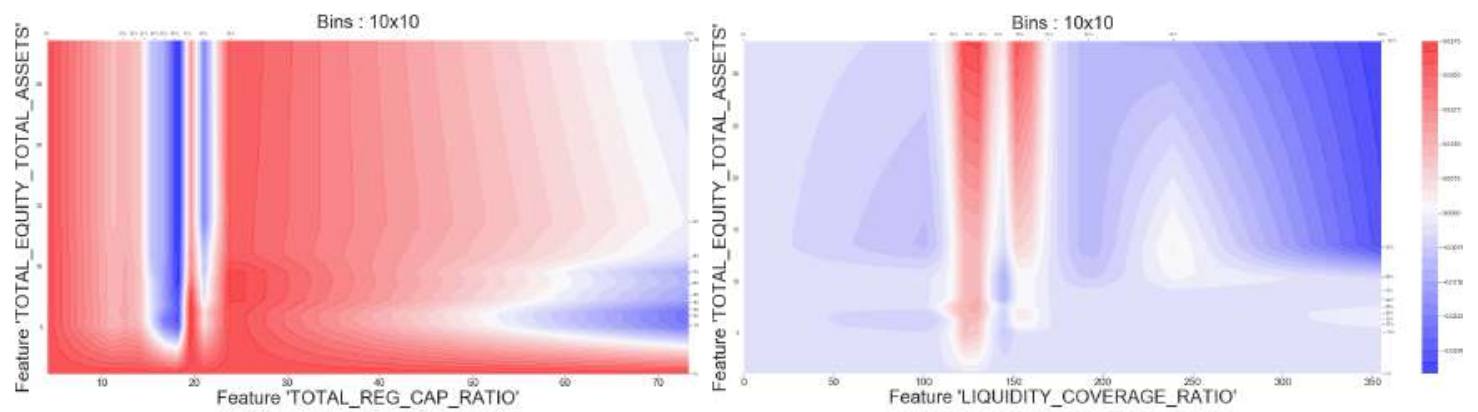

Source: Authors' calculations from FitchConnect data. The left plots display the impact of the interaction between $\frac{\mathrm{E}}{\mathrm{TA}}$ and LCR on ROAE, while the right plots show the impact of the interaction between $\frac{\mathrm{E}}{\mathrm{TA}}$ and TCR on ROAE.

To conclude, $\frac{\mathrm{E}}{\mathrm{TA}}$ has a negative but weak impact on ROAE. Implementing stronger equity requirements would therefore have an adverse impact on the shareholder value of banks. LCR also has a weak impact on ROAE. On the contrary, TCR has a strong non-linear effect on ROAE: a positive one below $16 \%$, and a negative or null one above this threshold. If banks look at maximizing their shareholder value, they are, therefore, incentivized to oppose strong equity requirements to prefer instead much complex capital ratios. This is precisely how current capital regulation is implemented. Having a look at the impact of regulatory variables on ROAE, we therefore manage to formulate an explanation to make sense of the paradox mentioned at the beginning of this section. Despite the positive impact of the ratio equity over total assets on banks' performance when measured as the ROAA, it is likely that banks oppose equity requirements since they negatively affect their shareholder value.

Once again, Lasso regressions (Table 3) confirm the results drawn from RF regressions. They indeed show that $\frac{E}{T A}$ and LCR have a weak and negative impact on ROAE. TCR's impact is shown to be negative in those models. This is because the highest values of TCR influence the relationship between this variable and ROAE when captured through Lasso models. 
Table 3 - Lasso regressions (ROAE as the dependent variable)

\begin{tabular}{c|cc}
\hline \hline \multirow{2}{*}{ Coefficient } & \multicolumn{2}{|c}{ Models } \\
\cline { 2 - 3 } & Lasso (AIC) & Lasso (BIC) \\
\hline$\frac{\mathrm{E}}{\mathrm{TA}}$ & -0.052 & 0 \\
TCR & -0.028 & -0.019 \\
LCR & 0 & 0 \\
\hline \hline
\end{tabular}

Source: Authors' calculations. ROAE is the dependent variable. Variables selection is done using both the Akaike information criterion (AIC) and the Bayes information criterion (BIC). A coefficient equal to 0 means that the variable has been excluded.

\section{Robustness}

\subsection{Results for other profitability variables}

To assess the robustness of our findings to the profitability measure, we use two other bank profitability variables (OPTA and NIM), and apply the same empirical approach as for ROAA and ROAE. The results are displayed in Appendix C.1.

The two models show high in-sample prediction performance, and higher out-of-sample $R^{2}$ than those of linear regressions in-sample (Table 5). The out-of sample explanatory power of RF regressions are $0.39 \%$ and $0.75 \%$. These results corroborate those obtained with ROAA and ROAE: RF models have sufficient predictive power to be trusted. Regarding the most important variables (Figure 12), and the place taken by the three regulatory ratios among these, the results also confirm those of the regression with ROAA: $\frac{\mathrm{E}}{\mathrm{TA}}$ and TCR take prominent places, except for the TCR in the model with NIM, and LCR never appears as a powerful predictor of the model. For both OPTA and NIM, the marginal impact of $\frac{\mathrm{E}}{\mathrm{TA}}$ is positive and quasi-linear (Figure 13). Results of TCR on OPTA confirm those obtained with ROAA: the effect of TCR being positive before and becoming null or negative beyond the optimum. In the two models, LCR shows positive impact on profitability. ${ }^{16}$ The interaction between $\frac{\mathrm{E}}{\mathrm{TA}}$ and profitability is confirmed in both models: the effect of the leverage ratio overcomes TCR and LCR impacts (Figures 14 and $15)$.

\footnotetext{
${ }^{16}$ PDPs and ALEs are not displayed here but are available upon request to the authors.
} 


\subsection{Results over 100 regressions}

$\mathrm{RF}$ regressions are designed in a way that allows them to take into account the existence of outliers in variables' distribution. However, Lasso models are not. Besides, in order to evaluate models' out-of-sample quality, we randomly selected $75 \%$ of our datasets. Therefore, and to be sure that all the data are taken into account, we run $100 \mathrm{RF}$ regressions and Lasso models forcing the data selection to over all deciles, and average the results. Doing so, we intend to confirm the superiority of RF quality over Lasso models insuring that out-of-sample $R^{2}$ remain higher even when accounting for outliers. In all cases, RF regressions are more adapted than linear models.

\subsection{Results in the large sample over 50 regressions}

We assess the validity of our results regarding the leverage and capital ratios. We aim to confirm the nature of the relation between those two regulatory requirements with profitability variables. To do so, we run RF regressions on our four profitability variables using a dataset of more than 15000 observations. ${ }^{17}$ To ensure the stability of our results, we average outcomes of $50 \mathrm{RF}$ regressions. The results of those regressions are displayed in Appendix C.2.

As shown, models' quality remains high (Table 6). The importance and positive impact of $\frac{\mathrm{E}}{\mathrm{TA}}$ on ROAA, OPTA and NIM is confirmed (Figures 16 and 17). A negative effect of this ratio on ROAE is detected when looking at this sample, but for high values of ROAE (Figure 17). The non-linear impact of TCR (positive below $16 \%$ and then negative) is confirmed in all models except for the one with profitability as measured by the NIM. ${ }^{18}$

\section{Conclusion}

Banking regulation currently faces multiple challenges: mitigating the specific risk associated with banking activities and allowing the transition towards a greener economy. Those objectives are not easy to deal with, and it is very tempting to define one rule per problem to solve. This is what has been done in the recent years: the solvency risk is dealt with through riskbased capital ratios, the liquidity risk through liquidity ratios, and the cost associated with banks' failures through bail-in standards. Banking regulation is thus made of multiple complex rules, whose implementation is often arguable. In this paper, we argue that another view on banking regulation could be adopted. Instead of the current multiplication of rules, we suggest implementing strong equity requirements. Such requirements would be simpler and more transparent than current rules, and would probably have a positive impact on the funding of long-term green assets.

\footnotetext{
${ }^{17}$ Note that this robustness check also allows us to confirm our results on US banks and a larger period (2000-2018).

${ }^{18}$ Due to space constraints, we did not displayed those results but they remain available on request.
} 
Strong equity requirements are however opposed by the banking industry, arguing that they would impede too much banks' activities. Resorting to RF regressions and to numerous robustness checks, we show that the ratio equity over total assets has on the contrary a positive impact on banks' performance when measured as the return on assets. Far from impeding banks' performance, equity requirements could instead foster it. We also find that capital and liquidity requirements do not hamper ROAA, except for high values of capital. Furthermore, we show that the equity over total asset ratio's impact broadly exceeds that of TCR and LCR. However, the ratio of equity over total assets displays most of the time a negative impact on the shareholder value of banks. In sum, the cost associated with equity requirements is not a social cost (a reduction in banks' performance), but a private cost entirely supported by shareholders. There is therefore no economic reason to oppose to stronger equity requirements.

Our paper also engages with the current debate surrounding the way financial regulation could tackle climate change. As famously put it by Mark Carney (Carney, 2015) financial regulation suffers from a "tragedy of horizons": it mainly focuses on short-term issues, while the time horizon of climate change is the long term. Breaking this tragedy requires extending the time horizon of both regulators and banks. Focusing on equity - which by definition is a stable source of funding - could allow to make one step in this direction.

\section{References}

V. V. Acharya, D. Gale, and T. Yorulmazer. Rollover risk and market freezes. Journal of Finance, 66(4):1177-1209, 2011. 6

A. R. Admati, P. M. DeMarzo, M. F. Hellwig, and P. C. Pfleiderer. Fallacies, irrelevant facts, and myths in the discussion of capital regulation: why bank equity is not socially expensive. Max Planck Institute for Research on Collective Good, 2013. 1, 2, 4, 5, 6

U. Albertazzi and L. Gambacorta. Bank profitability and the business cycle. Journal of Financial Stability, 5(4):393 - 409, 2009. ISSN 1572-3089. 3, 9

A. Baker. The new political economy of the macroprudential ideational shift. New Political Economy, 18(1):112-139, 2013. 4

M. Baker and J. Wurgler. Do Strict Capital Requirements Raise the Cost of Capital? Bank Regulation, Capital Structure, and the Low-Risk Anomaly. The American Economic Review, 105(5):315-320, 2015. 3

M. Balling. Modigliani-miller, basel 3 and crd 4. SUERF Policy Notes, (2):1-8, 2015.

A. Berger. The Relationship between Capital and Earnings in Banking. Journal of Money, Credit and Banking, 27(2):432-56, 1995. 2, 9 
A. Berger, R. J. Herring, and G. Szego. The Role of Capital in Financial Institutions. Center for Financial Institutions Working Papers, 1995. 9

A. N. Berger and C. Bouwman. Bank Liquidity Creation. Review of Financial Studies, 22(9): 3779-3837, 2009. 3

P. Bologna, A. Miglietta, and A. Segura. Contagion in the coco bonds market? A case study of two stress events. Bank of Italy Working Paper, 2018. 4

P. Bolton, S. Cecchetti, J.-P. Danthine, and X. Vives. Sound At Last? Assessing a Decade of Financial Regulation. CEPR Press, 2019. 5

P. Bolton, M. Després, L. A. Pereira da Silva, F. Samama, and R. Svartzman. The green swan - Central banking and financial stability in the age of climate change. Bank for International Settlements and Bank of France Working Paper, 2020. 5

E. Bordeleau and C. Graham. The Impact of Liquidity on Bank Profitability. Bank of Canada, (10-38), 2010. 3

C. Borio, L. Gambacorta, and B. Hofmann. The influence of monetary policy on bank profitability. International Finance, 20:48-63, 04 2017. 3

P. Bourke. Concentration and other determinants of bank profitability in Europe, North America and Australia. Journal of Banking \& Finance, 13(1):65 - 79, 1989. ISSN 0378-4266. 3

L. Breiman. Random Forests. Machine Learning, 45(1):5-32, Oct 2001. ISSN 1573-0565. doi: 10.1023/A:1010933404324. 7

L. Breiman, J. Friedman, R. Olshen, and C. Stone. Classification and Regression Trees. 1984. 8

M. Brunnermeier. Deciphering the liquidity and credit crunch 2007-2008. Journal of Economic Perpectives, 23(1):77-100, 2009. 1

E. Campiglio. Beyond carbon pricing: The role of banking and monetary policy in financing the transition to a low-carbon economy. Ecological Economics, 121:220-230, 2016. 6

M. Carney. Breaking the tragedy of the horizon - climate change and financial stability. 2015. 22

N. C. Chia and J. Whalley. The Tax Treatment of Financial Intermediation. Journal of Money, Credit and Banking, 31(4):704-19, 1999. 3

J. M. Corcuera, J. De Spiegeleer, J. Fajardo, H. Jönsson, W. Schoutens, and A. Valdivia. Close form pricing formulas for coupon cancellable cocos. Journal of Banking $\&$ Finance, 42(1): 339-351, 2014. 4 
A. Datta, S. Sen, and Y. Zick. Algorithmic transparency via quantitative input influence: Theory and experiments with learning systems. pages 598-617, 05 2016. doi: 10.1109/SP.2016.42. 8

R. DeYoung and T. Rice. Non Interest Income and Financial Performance at US Commercial Banks. Financial Review, 39:101 - 127, 022004.

A. Dietrich and G. Wanzenried. The determinants of commercial banking profitability in low-, middle-, and high-income countries. The Quarterly Review of Economics and Finance, 54(3): 337 - 354, 2014. ISSN 1062-9769. 3

I. Distinguin, C. Roulet, and A. Tarazi. Bank Regulatory Capital and Liquidity: Evidence from U.S. and European Publicly Traded Banks. Journal of Banking \& Finance, 37, 03 2013. 9

J. Friedman. Greedy function approximation: A gradient boosting machine. The Annals of Statistics, 29, 11 2000. doi: 10.1214/aos/1013203451. 8

L. Gambacorta and H. S. Shin. Why bank capital matters for monetary policy? Journal of Financial Intermediation, 35(B):17-29, July 2018. 1

A. García-Herrero, S. Gavilá, and D. Santabárbara. What explains the low profitability of Chinese banks? Journal of Banking \& Finance, 33(11):2080-2092, November 2009. 3

J. Goddard, H. Liu, P. Molyneux, and J. O. Wilson. Do Bank Profits Converge? European Financial Management, 19(2):345-365, 2013. 3

C. Goodhart. Problems of monetary management: The U.K. experience. Papers in monetary economics Reserve Bank of Australia, 1975. 5

R. Gropp and F. Heider. The Determinants of Bank Capital Structure. Review of Finance, 14 (4):587-622, 032010.

T. Hastie, R. Tibshirani, and J. Friedman. The Elements of Statistical Learning: Data Mining, Inference, and Prediction. Springer series in statistics. Springer, 2009. ISBN 9780387848846. $2,7,8$

G. Iannotta, G. Nocera, and A. Sironi. Ownership structure, risk and performance in the European banking industry. Journal of Banking \& Finance, 31(7):2127 - 2149, 2007. View Online. 2

M. C. Keeley. Deposit Insurance, Risk, and Market Power in Banking. American Economic Review, 80(5):1183-1200, December 1990.

A. Kraus and R. H. Litzenberger. A State-Preference Model of Optimal Financial Leverage. Journal of Finance, 28(4):911-22, 1973. 
G. Le Quang. Mind the conversion risk: a theoretical assessment of contingent convertible bonds. EconomiX Worping Paper, 2019. 4

C.-C. Lee and M.-F. Hsieh. The impact of bank capital on profitability and risk in Asian banking. Journal of International Money and Finance, 32:251 - 281, 2013. 2

M. Miller. Do the M \& M propositions apply to banks? Journal of Banking \& Finance, 19 (3-4):483-489, 1995.

F. Modigliani and M. H. Miller. The Cost of Capital, Corporation Finance and the Theory of Investment. The American Economic Review, 48(3):261-297, 1958. ISSN 00028282.

P. Molyneux and J. Thornton. Determinants of European bank profitability: A note. Journal of Banking \& Finance, 16(6):1173-1178, December 1992. 3

S. Morris and H. S. Shin. Illiquidity component of credit risk - the 2015 Lawrence R. Klein Lecture. International Economic Review, 57(4):1135-1148, 2016. 6

M. Osborne, A.-M. Fuertes, and A. Milne. Capital and profitability in banking : Evidence from us banks. 2012. Working Paper. 9

T. M. Oshiro, P. S. Perez, and J. A. Baranauskas. How Many Trees in a Random Forest? In P. Perner, editor, Machine Learning and Data Mining in Pattern Recognition, pages 154-168, Berlin, Heidelberg, 2012. Springer Berlin Heidelberg. ISBN 978-3-642-31537-4. 8

A. Persaud. Why bail-in securities are fool's gold. Peterson Institute for International Economics Policy Briefs, PB14-23, 2014. 4

R. Tibshirani. Regression Shrinkage and Selection via the Lasso. Journal of the Royal Statistical Society. Series B (Methodological), 58(1):267-288, 1996. ISSN 00359246. 11

V. T. Tran, C.-T. Lin, and H. Nguyen. Liquidity creation, regulatory capital, and bank profitability. International Review of Financial Analysis, 48(C):98-109, 2016. 9

T. Xu, K. Hu, and S. Das, Udaibir. Bank Profitability and Financial Stability. IMF Working Paper, 2019. 9 


\section{A Data sources and definitions}

Table 4 - Data sources and definitions

\begin{tabular}{|c|c|c|}
\hline Data & Definition & Source \\
\hline $\begin{array}{l}\text { TOTAL REG CAP RA- } \\
\text { TIO }\end{array}$ & $\begin{array}{l}\text { Total regulatory capital ratio as defined un- } \\
\text { der Basel agreements. It is fixed to } 8 \% \text { of the } \\
\text { risk weighted assets, plus a conservation buffer } \\
(2 \%) \text {. }\end{array}$ & FitchConnect \\
\hline $\begin{array}{l}\text { LIQUIDITY COVER- } \\
\text { AGE RATIO }\end{array}$ & $\begin{array}{l}\text { Short term liquidity ratio as define under } \\
\text { Basel III agreements. Ratio of High Quality } \\
\text { Liquid Assets to cash flow under stress. }\end{array}$ & FitchConnect \\
\hline $\begin{array}{l}\text { RESERVE NPL GROSS } \\
\text { LOANS }\end{array}$ & $\begin{array}{l}\text { Ratio of volume of NPL to gross loans. It gives } \\
\text { a measure of credit risks took by a bank. }\end{array}$ & FitchConnect \\
\hline $\begin{array}{l}\text { LOAN CUSTOMER DE- } \\
\text { POSITS }\end{array}$ & $\begin{array}{l}\text { Loan to customer deposit accounts, which can } \\
\text { be withdrawn on demand or short notice. }\end{array}$ & FitchConnect \\
\hline $\begin{array}{lll}\text { LOAN } & \text { LOSS } & \text { PROVI- } \\
\text { SION } & & \\
\end{array}$ & $\begin{array}{l}\text { Provision made by a bank to hedge against } \\
\text { loan losses. }\end{array}$ & FitchConnect \\
\hline $\begin{array}{lcr}\text { LOAN } & \text { LOSS } & \text { PROVI- } \\
\text { SION } & \text { GROSS } & \text { LOAN } \\
\text { AVG } & & \\
\end{array}$ & & FitchConnect \\
\hline $\begin{array}{l}\text { DEPOSITS MM FUND- } \\
\text { ING GROWTH }\end{array}$ & $\begin{array}{l}\text { Growth rate of deposits to money market } \\
\text { funding. }\end{array}$ & FitchConnect \\
\hline $\begin{array}{l}\text { TOTAL EQUITY } \text { TO- } \\
\text { TAL ASSETS }\end{array}$ & $\begin{array}{l}\text { Ratio of total equity to total assets. This ratio } \\
\text { is close to the leverage ratio as defined under } \\
\text { Basel agreements. }\end{array}$ & FitchConnect \\
\hline TOTAL LIABILITIES & Liabilities of each bank. & FitchConnect \\
\hline INT EXP AVG INT LIAB & $\begin{array}{l}\text { Ratio of total interest expense / average } \\
\text { interest-bearing liabilities. }\end{array}$ & FitchConnect \\
\hline $\begin{array}{lll}\text { AVG } & \text { INT } & \text { BEARING } \\
\text { LIAB } & & \\
\end{array}$ & Average interest-bearing liabilities & FitchConnect \\
\hline LIQUIDITY ASSETS GS & Liquid assets detained by the bank & FitchConnect \\
\hline $\begin{array}{l}\text { NET LOANS TOTAL } \\
\text { EQUITY }\end{array}$ & Ratio of net loans to total equity. & FitchConnect \\
\hline $\begin{array}{l}\text { NET LOANS TOTAL } \\
\text { ASSETS }\end{array}$ & Ratio of net loans to total assets. & FitchConnect \\
\hline $\begin{array}{ll}\text { GROSS } & \text { LOANS } \\
\text { GROWTH } & \end{array}$ & Growth rate of gross loans. & FitchConnect \\
\hline
\end{tabular}


Table 4 - (continued)

\begin{tabular}{|c|c|c|}
\hline TOTAL ASSETS & $\begin{array}{l}\text { Total assets of the bank. Often used as a size } \\
\text { proxy. }\end{array}$ & FitchConnect \\
\hline $\begin{array}{l}\text { CUSTOMER DEPOSITS } \\
\text { TOTAL FUND DER }\end{array}$ & Ratio of customer deposits to total fund. & FitchConnect \\
\hline DEPOSITS ASSETS & $\begin{array}{l}\text { Money placed into banking institutions for } \\
\text { safekeeping. }\end{array}$ & FitchConnect \\
\hline BUS VOLUME & $\begin{array}{l}\text { Managed Securitized Assets Reported Off- } \\
\text { Balance Sheet }+ \text { Other off-balance sheet ex- } \\
\text { posure to securitizations + Guarantees + Ac- } \\
\text { ceptances and documentary credits reported } \\
\text { off-balance sheet + Committed Credit Lines } \\
+ \text { Other Contingent Liabilities + Total Assets }\end{array}$ & FitchConnect \\
\hline $\begin{array}{lll}\text { TOTAL OPER EX- } \\
\text { PENSE }\end{array}$ & $\begin{array}{l}\text { Operating costs include administration costs } \\
\text { such as staff costs. }\end{array}$ & FitchConnect \\
\hline TOTAL NON INT EXP & $\begin{array}{l}\text { Operating expense that is classified separately } \\
\text { from interest expense and provision for credit } \\
\text { losses. }\end{array}$ & FitchConnect \\
\hline OTHER OPER EXP & Operating expenses. & FitchConnect \\
\hline TOTAL FUNDING & $\begin{array}{l}\text { Total Deposits, Money Market and Short- } \\
\text { term Funding }+ \text { Total Long Term Funding }+ \\
\text { Derivatives }+ \text { Trading Liabilities }\end{array}$ & FitchConnect \\
\hline TOTAL INT EXP & Interests on expenses costs. & FitchConnect \\
\hline TOTAL DEPOSITS & Total deposits. & FitchConnect \\
\hline TAX EXPENSE & $\begin{array}{l}\text { Expense for current and deferred tax for the } \\
\text { period. }\end{array}$ & \\
\hline OTHER INT EXP & Interest expenses. & FitchConnect \\
\hline $\begin{array}{lll}\text { OTHER NON } & \text { INT } \\
\text { BEARING GS } & \end{array}$ & Non interest-bearing. & FitchConnect \\
\hline $\begin{array}{l}\text { TOTAL NON EARNING } \\
\text { ASSETS }\end{array}$ & All assets that do not generate income. & FitchConnect \\
\hline NON EARNING ASSETS & Assets that do not generate income. & FitchConnect \\
\hline $\begin{array}{l}\text { TOTAL EARNING AS- } \\
\text { SETS }\end{array}$ & All assets that generate income. & FitchConnect \\
\hline $\begin{array}{l}\text { OTHER NON EARNING } \\
\text { ASSETS }\end{array}$ & Other assets that do not generate income. & FitchConnect \\
\hline OTHER ASSETS & Other assets & FithConnect \\
\hline
\end{tabular}


Table $4-($ continued)

\begin{tabular}{l|l|c}
\hline HHI & $\begin{array}{l}\text { Herfindahl-Hirschman Index. Gives a measure } \\
\text { of the market concentration. }\end{array}$ & FitchConnect \\
\hline CashAndDepositsBank & Cash and deposits from other banks. & FitchConnect \\
\hline Inflation & Annual inflation rate. & OECD \\
\hline GrGDPperCap & Annual GDP growth rate per capita. & World Bank \\
\hline Corp Tax & Corporate tax rate. & OECD \\
\hline \hline
\end{tabular}

\section{B Descriptive statistics}

Figure 11 - Number of banks' evolution

(a) With LCR

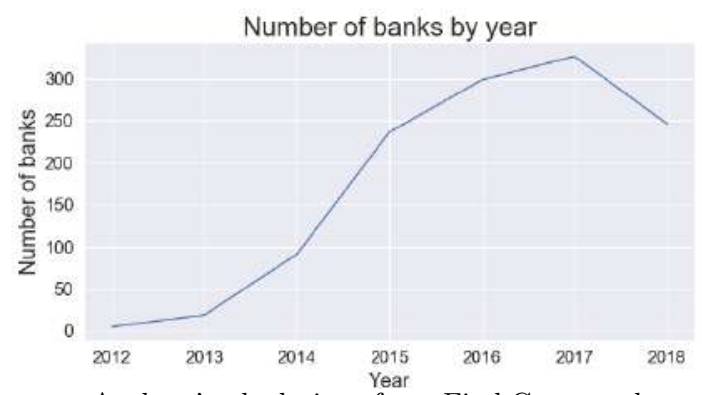

(b) Without LCR

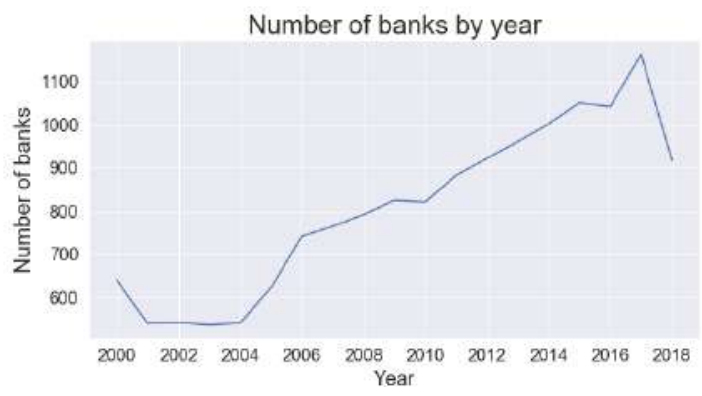

Source: Authors' calculations from FitchConnect data.

\section{Robustness outputs}

\section{C.1 Results for other profitability variables}

Figure 12 - Variables' Importance - ROAE, OPTA, NIM

(a) OPTA

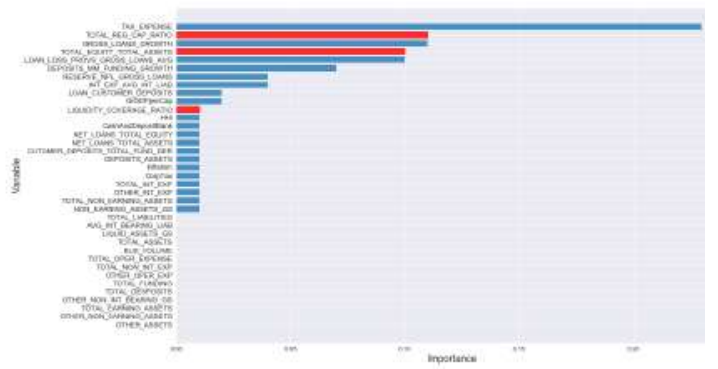

Source: Authors' calculations from FitchConnect data. (b) NIM

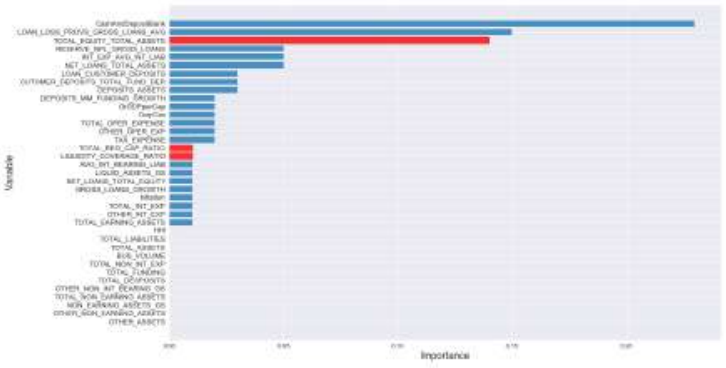


Table 5 - Model's quality: RF versus Lasso

(a) OPTA as the dependent variable

\begin{tabular}{c|ccc}
\hline \hline \multirow{2}{*}{ Sample } & \multicolumn{3}{|c}{ Models } \\
\cline { 2 - 4 } & RF & Lasso (AIC) & Lasso (BIC) \\
\hline In-sample & 0.85 & 0.24 & 0.22 \\
Out-of-sample & 0.39 & 0.15 & 0.14 \\
\hline \hline
\end{tabular}

(b) NIM as the dependent variable

\begin{tabular}{c|ccc}
\hline \hline \multirow{2}{*}{ Sample } & \multicolumn{3}{|c}{ Models } \\
\cline { 2 - 4 } & RF & Lasso (AIC) & Lasso (BIC) \\
\hline In-sample & 0.92 & 0.48 & 0.47 \\
Out-of-sample & 0.75 & 0.42 & 0.41 \\
\hline \hline
\end{tabular}

Source: Authors' calculations. The table shows the coefficient of determination $\left(R^{2}\right)$ scores. In the Lasso model, variables selection is done using both the Akaike information criterion (AIC) and the Bayes information criterion (BIC).

Figure 13 - PDPs and ALEs of $\frac{E}{\text { TA }}$

(a) Dependent variable: OPTA
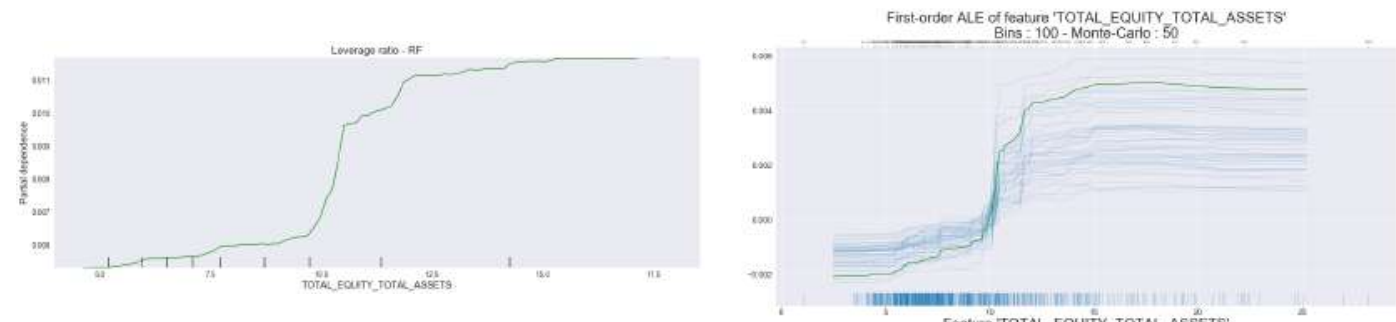

(b) Dependent variable: NIM
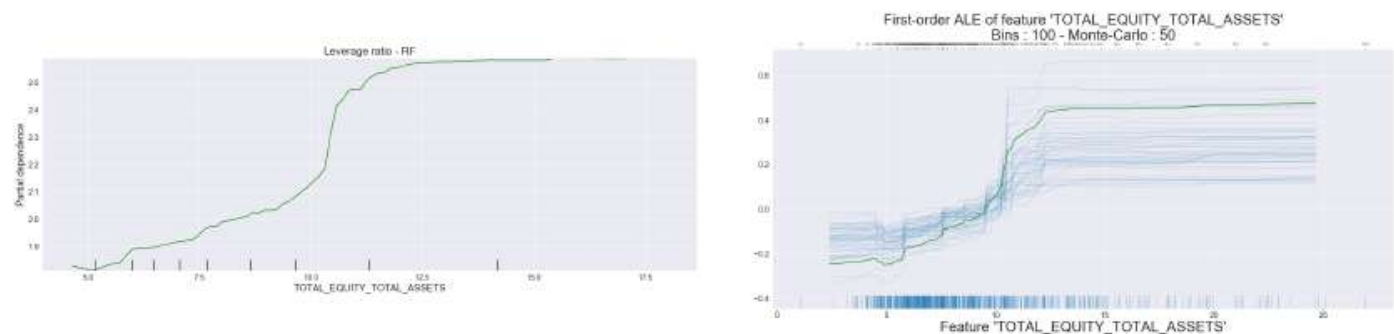

Source: Authors' calculations from FitchConnect data. 
Figure 14 - Dependent variable: OPTA

(a) Two ways PDP and ALE - $\frac{E}{T A}$ and TCR
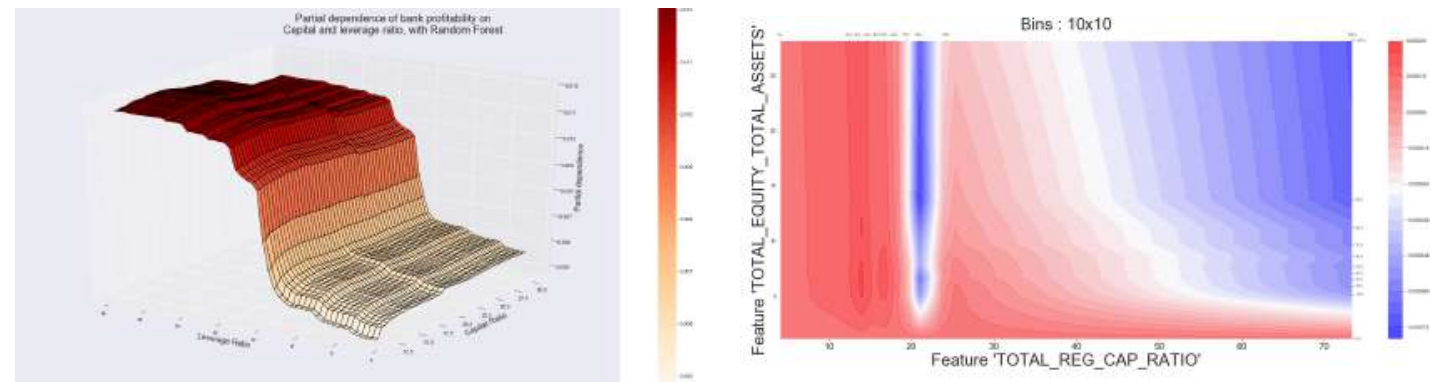

(b) Two ways PDP and ALE - $\frac{E}{T A}$ and LCR
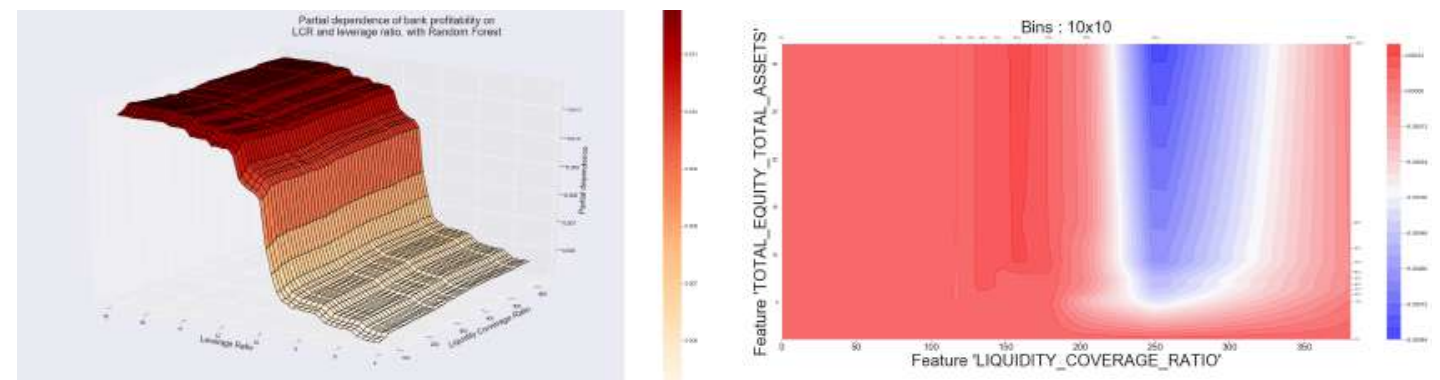

Source: Authors' calculations from FitchConnect data.

Figure 15 - Dependent variable: NIM

(a) Two ways PDP and ALE - $\frac{E}{T A}$ and TCR
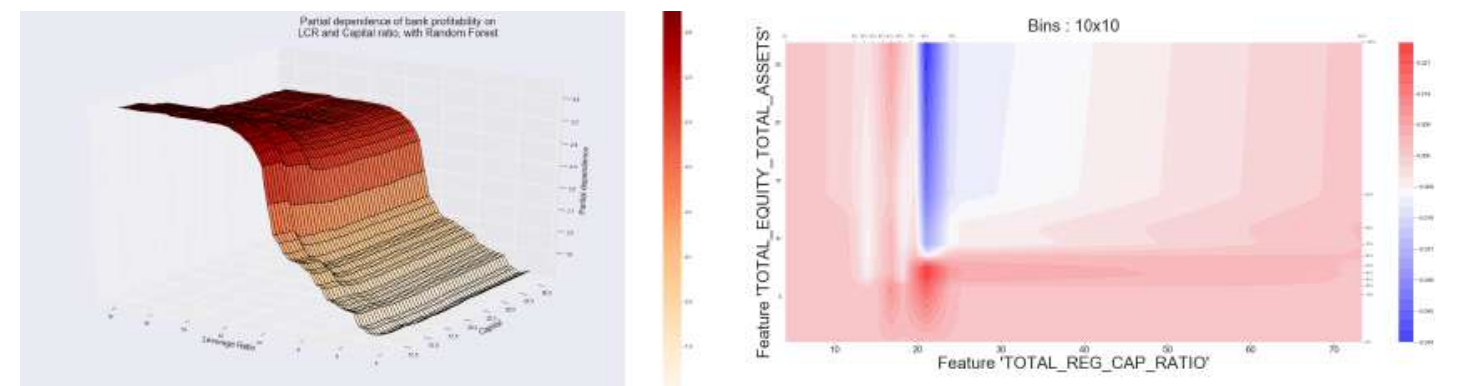

(b) Two ways PDP and ALE - $\frac{E}{\text { TA }}$ and LCR
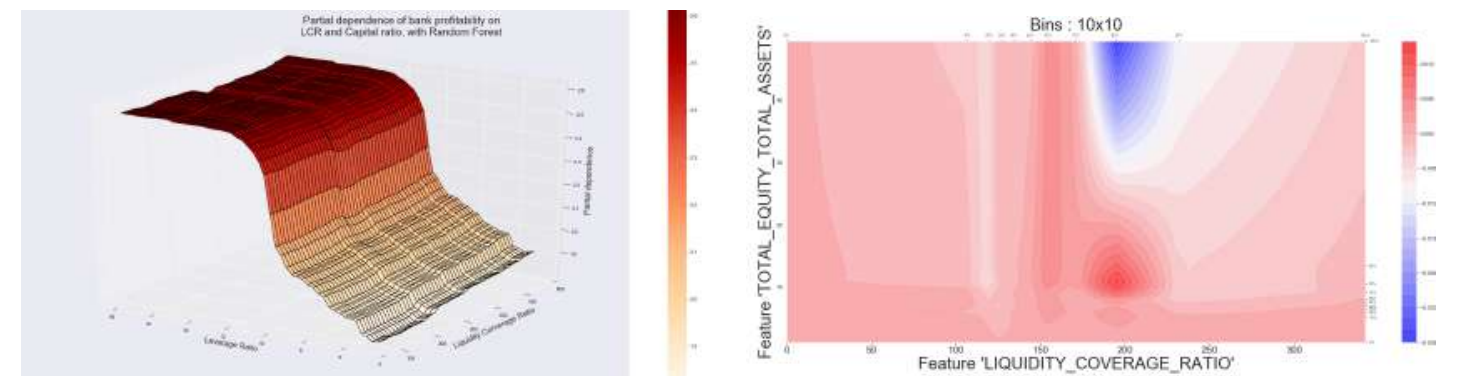

Source: Authors' calculations from FitchConnect data. 


\section{C.2 Results in large sample over 50 regressions}

Table 6 - Model's quality: RF versus Lasso

(a) ROAA as the dependent variable

\begin{tabular}{c|ccc}
\hline \hline \multirow{2}{*}{ Sample } & \multicolumn{3}{|c}{ Models } \\
\cline { 2 - 4 } & RF & Lasso (AIC) & Lasso (BIC) \\
\hline In-sample & 0.86 & 0.28 & 0.26 \\
Out-of-sample & 0.49 & 0.14 & 0.09 \\
\hline \hline
\end{tabular}

(b) ROAE as the dependent variable

\begin{tabular}{c|ccc}
\hline \hline \multirow{2}{*}{ Sample } & \multicolumn{3}{|c}{ Models } \\
\cline { 2 - 4 } & RF & Lasso (AIC) & Lasso (BIC) \\
\hline In-sample & 0.7 & 0.12 & 0.12 \\
Out-of-sample & 0.42 & 0.11 & 0.11 \\
\hline \hline
\end{tabular}

(c) OPTA as the dependent variable

\begin{tabular}{c|ccc}
\hline \hline \multirow{2}{*}{ Sample } & \multicolumn{3}{|c}{ Models } \\
\cline { 2 - 4 } & RF & Lasso (AIC) & Lasso (BIC) \\
\hline In-sample & 0.77 & 0.14 & 0.13 \\
Out-of-sample & 0.37 & 0.06 & 0.07 \\
\hline \hline
\end{tabular}

(d) NIM as the dependent variable

\begin{tabular}{c|ccc}
\hline \hline \multirow{2}{*}{ Sample } & \multicolumn{3}{|c}{ Models } \\
\cline { 2 - 4 } & RF & Lasso (AIC) & Lasso (BIC) \\
\hline In-sample & 0.85 & 0.37 & 0.36 \\
Out-of-sample & 0.67 & 0.36 & 0.36 \\
\hline \hline
\end{tabular}

Source: Authors' calculations. The table shows the coefficient of determination $\left(R^{2}\right)$ scores. In the Lasso model, variables selection is done using both the Akaike information criterion (AIC) and the Bayes information criterion (BIC). 
Figure 16 - Variables' Importance in large sample - ROAE, OPTA, NIM

(a) ROAA

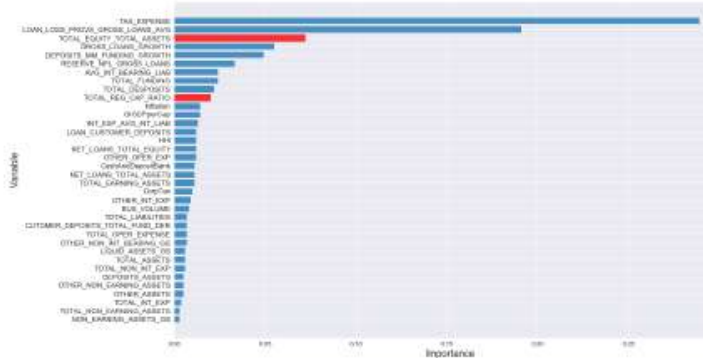

(c) OPTA

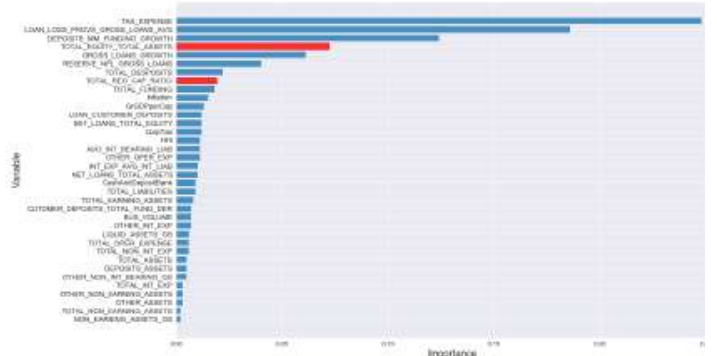

(b) ROAE

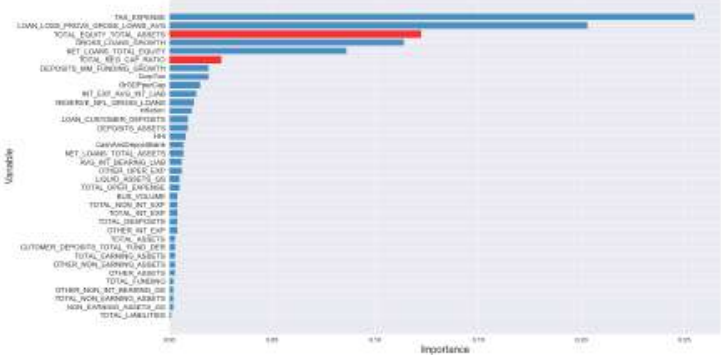

(d) NIM

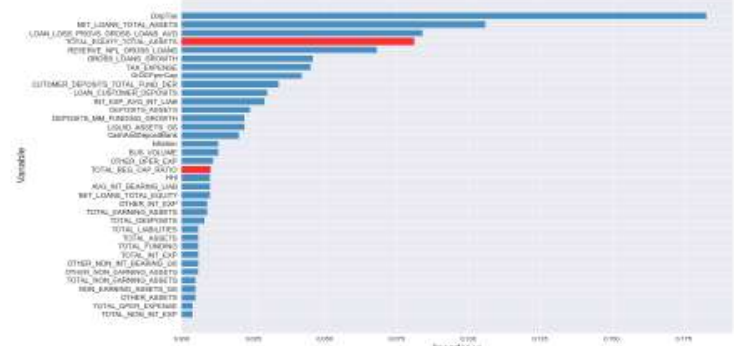

Source: Authors' calculations from FitchConnect data.

Figure 17 - PDPs of $\frac{E}{\mathrm{TA}}$ in large sample

(a) ROAA

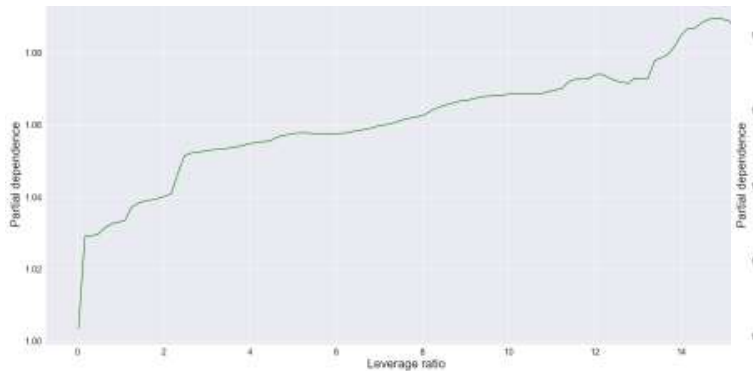

(c) OPTA

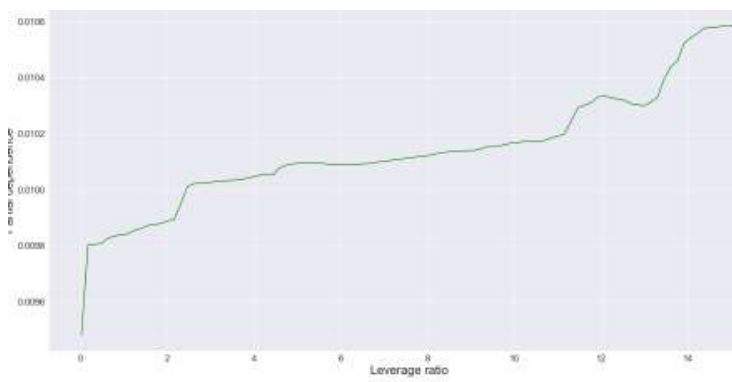

Source: Authors' calculations from FitchConnect data. (b) ROAE

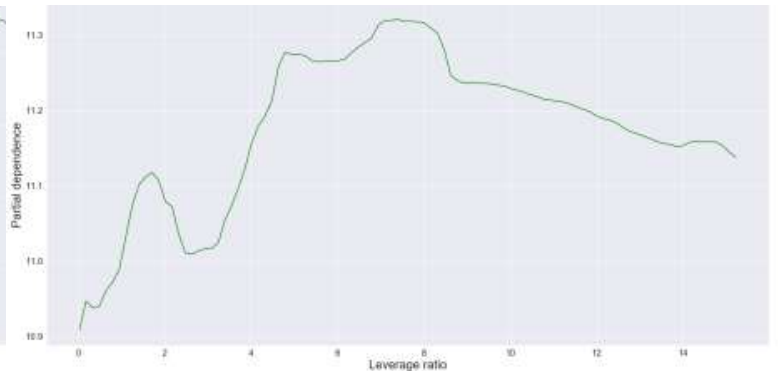

(d) NIM

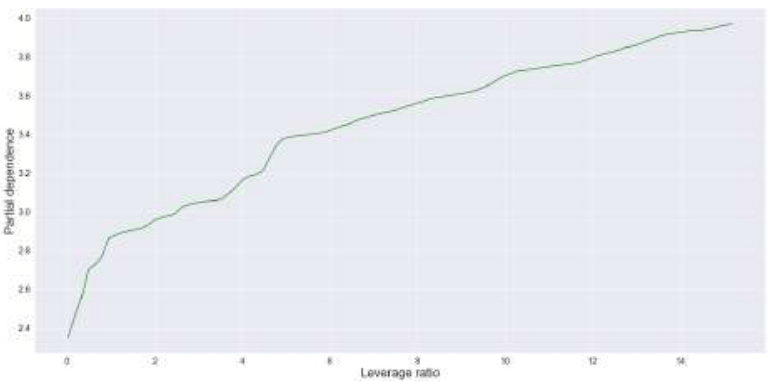

